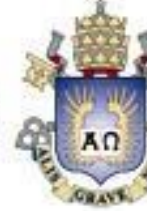

André de Brito Arueira

\title{
Aplicação do Método AHP para Avaliação de \\ Transportadores
}

Dissertação apresentada como requisito parcial para obtenção do grau de Mestre (Opção Profissional) pelo Programa de Pós-Graduação em Engenharia de Produção do Departamento de Engenharia Industrial da PUC-Rio.

Orientador: Prof. Hugo Varela Repolho 


\section{Aplicação do Método AHP para Avaliação de \\ Transportadores}

Dissertação apresentada como requisito parcial para obtenção do grau de Mestre (Opção Profissional) pelo Programa de Pós-Graduação em Engenharia de Produção do Departamento de Engenharia Industrial da PUC-Rio. Aprovada pela Comissão Examinadora abaixo assinada.

Prof. Hugo Varela Repolho

Orientador

Departamento de Engenharia Industrial - PUC-Rio

Prof. José Eugênio Leal

Departamento de Engenharia Industrial - PUC-Rio

Prof. Vânia Barcelos Gouvêa Campos

Programa de Mestrado em Engenharia de Transportes - IME/RJ

Prof. José Eugênio Leal

Coordenador Setorial do

Centro Técnico Científico - PUC-Rio

Rio de Janeiro, 04 de Setembro de 2014 
Todos os direitos reservados. É proibida a reprodução total ou parcial do trabalho sem autorização da universidade, do autor e do orientador.

\section{André de Brito Arueira}

Graduou-se em administração industrial pelo CEFET-RJ (Centro Federal de Educação Tecnológica Celso Suckow da Fonseca), em Julho de 2009. Cursou MBA em Logística Empresarial Gestão da Cadeia de Suprimentos na UFF (Universidade Federal Fluminense), em Julho de 2011. Atualmente atua como coordenador logístico da COMLURB (Companhia Municipal de Limpeza Urbana do Rio de Janeiro), responsável pela implantação de área de monitoramento e controle logístico.

Ficha Catalográfica

Arueira, André de Brito

Aplicação do método AHP para avaliação de transportadores / André de Brito Arueira ; orientador: Hugo Varela Repolho. - 2014.

71 f. : il. (color.) ; $30 \mathrm{~cm}$

Dissertação (mestrado)-Pontifícia Universidade Católica do Rio de Janeiro, Departamento de Engenharia Industrial, 2014.

Inclui bibliografia

1. Engenharia Industrial - Teses. 2. Gerenciamento de fornecedores. 3. Prestadores de serviço logístico. 4. Analytic Hierarchy Process. 5. Avaliação de desempenho. I. Repolho, Hugo Varela. II. Pontifícia Universidade Católica do Rio de Janeiro. Departamento de Engenharia Industrial. III. Título. 

carinho e auxílio. 


\section{Agradecimentos}

Agradeço a minha noiva, Bruna, por me apoiar e me incentivar a continuar estudando e buscando maior qualificação.

Agradeço a minha família por sempre me apoiar em todos os momentos da minha vida e por acreditar que seria capaz de vencer mais esse desafio. À minha "Tia" Helen e sua família por me acolher em sua casa nos dias de aula e me dar um verdadeiro lar nesse período.

Agradeço ao professor Hugo Repolho, pela orientação e tempo disponibilizado para apoiar o desenvolvimento deste trabalho com transferência de conhecimento e críticas construtivas.

Agradeço empresa estudada por disponibilizar as informações necessárias para desenvolvimento do trabalho e me apoiar durante todo o seu desenvolvimento. À PUC-Rio e a escola de engenharia industrial, pelo ensino de qualidade e pelo alto nível dos profissionais que contribuíram para meu desenvolvimento pessoal e profissional.

Por fim, agradeço aos companheiros de mestrado Alan Guerra, Guilherme Nunes e Maurício Prada, pela amizade, pelo compartilhamento do conhecimento e experiências e pela parceria nos desafios acadêmicos que foram vencidos. 


\section{Resumo}

Arueira, André de Brito; Repolho, Hugo Varela. Aplicação do Método

AHP para Avaliação de Transportadores. Rio de Janeiro, 2014. 71p.

Dissertação de Mestrado - Departamento de Engenharia, Pontifícia

Universidade Católica do Rio de Janeiro.

É notório no meio acadêmico e prático que ao longo dos últimos anos a logística deixou de ser vista como um processo operacional e passou a ser reconhecida como uma matéria de suma importância na integração das cadeias de suprimentos e uma ferramenta importante para atender as necessidades dos clientes e buscar diferencial competitivo. Em um ambiente globalizado e competitivo, as empresas buscam soluções que possam ajudá-las a atingir seus objetivos organizacionais. Neste contexto, a terceirização de serviços logísticos vem sendo amplamente utilizada com diversas finalidades. Porém, ao realizar terceirizações logísticas as empresas se deparam com a dificuldade de desenvolver mecanismos de avaliação de desempenho que estejam alinhados com a estratégia das empresas e que possam avaliar dados quantitativos e qualitativos para mensurar e comparar o desempenho de seus terceirizados. Diante deste cenário, este trabalho apresenta um estudo de caso onde foi utilizado o método AHP (Analytic Hierarchy Process) como ferramenta de apoio para avaliação, ranking e reconhecimento de transportadores terceirizados de uma multinacional líder de mercado de gases industriais e medicinais. Existe uma relação entre a satisfação do cliente final e o desempenho dos transportadores. Portanto, é fundamental o desenvolvimento de uma ferramenta para mensurar esse desempenho e reconhecer os melhores. O trabalho propõe a avaliação dos transportadores através de um único índice que traduz indicadores quantitativos e qualitativos. A escolha do método AHP foi fundamental para facilitar a estruturação do problema e se 
mostrou uma ferramenta de fácil entendimento tanto para o pesquisador como para os demais envolvidos.

\section{Palavras-chave}

Terceirização; Avaliação de Desempenho; Prestadores de Serviços Logísticos; Analytic Hierarchy Process; Gestão de Fornecedores; Gestão de Contratos. 


\section{Abstract}

Arueira, André de Brito; Repolho, Hugo Varela (Advisor). Application of AHP Method for Evaluation of Carriers. Rio de Janeiro, 2014. 71p.

MSc. Dissertation - Departamento de Engenharia, Pontifícia Universidade Católica do Rio de Janeiro.

It is well known in the academic and practical means that over the last few years the logistics is no longer seen as an operational process and has become recognized as a matter of paramount importance in the integration of supply chains and an important tool to meet customer needs and seek competitive advantage. In a globalized and competitive environment, companies are looking for solutions that can help them achieve their organizational goals. In this context, the outsourcing of logistics services has been widely used for various purposes. However, when performing logistics outsourcing companies are faced with the difficulty of developing mechanisms for evaluating performance that are aligned with company strategy and to assess quantitative and qualitative data to measure and compare the performance of their third party. This paper presents a case study where the AHP (Analytic Hierarchy Process) method was used as a support tool for evaluation, ranking and recognition outsourced carriers of a multinational leader in industrial and medical gases market on Brazil. There is a relationship between the end-customer satisfaction and the performance of carriers. Therefore, it is fundamental to develop a tool to measure this performance and recognize the best carrier. The paper proposes the review of carriers through a single index reflecting quantitative and qualitative indicators. The choice of AHP was instrumental in facilitating the structuring of the problem and proved to be an easily understood tool for researchers and for the others involved. 


\section{KeyWords}

Outsourcing; Performance Evaluation; logistics providers; Analytic Hierarchy Process; Supplier Management; Contract Management. 


\section{Sumário}

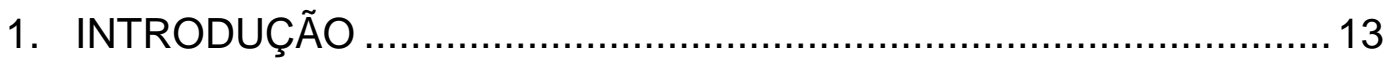

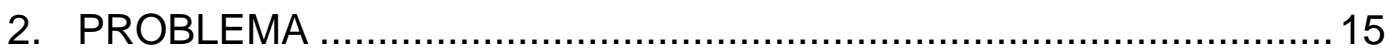

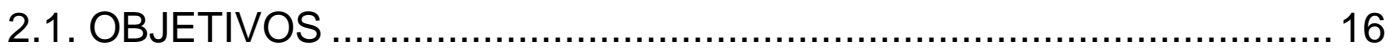

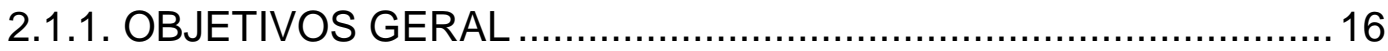

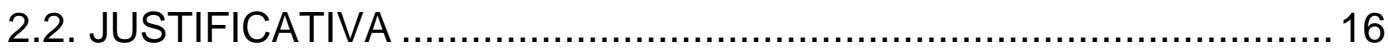

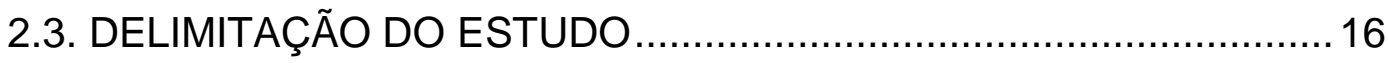

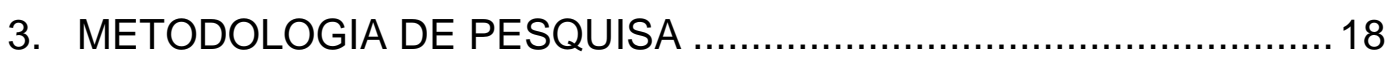

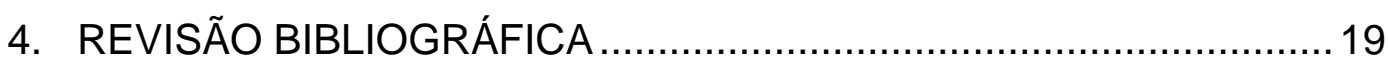

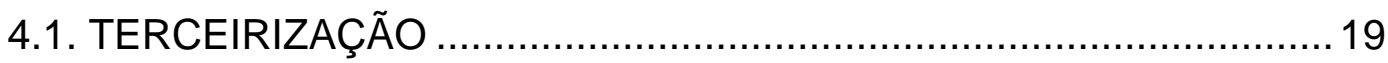

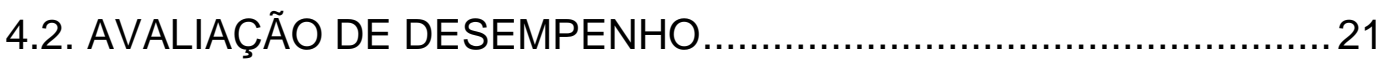

4.2.1 AVALIAÇÃO DE DESEMPENHO LOGÍSTICO ..............................23

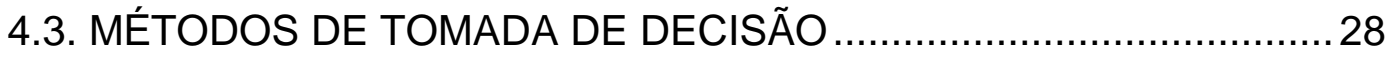

4.3.1 TÉCNICAS DE TOMADA DE DECISÃO ……..............................29

4.3.2 JUSTIFICATIVA DO MÉTODO ESCOLHIDO .................................35

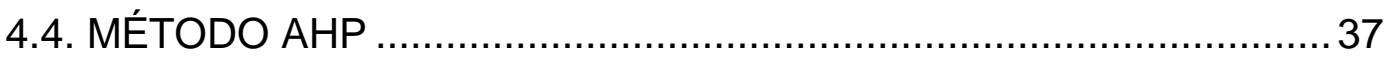

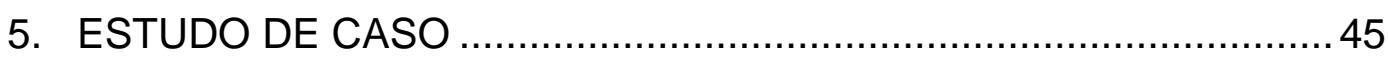

5.1. ESCOLHA DE CRITÉRIOS E INDICADORES E CONSTRUÇÃO DA

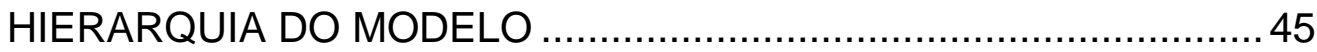

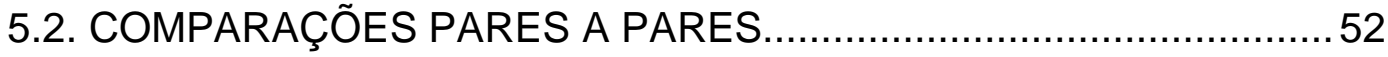

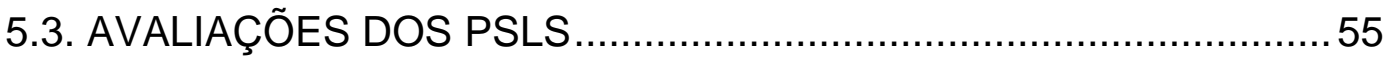

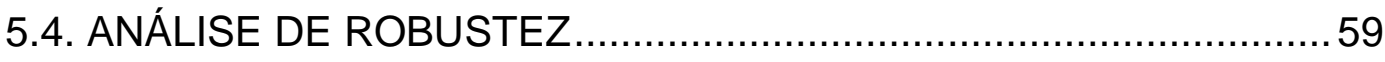

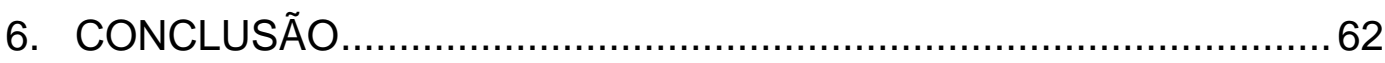

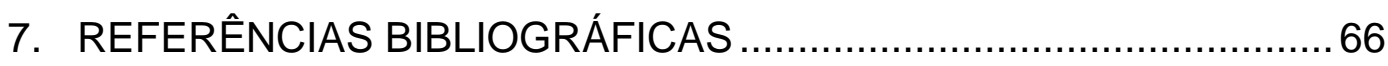




\section{Lista de Figuras}

FIGURA 1: ATIVIDADES TERCEIRIZADAS EM 2006 .........................21

FIGURA 2: ESTRUTURAÇÃO HIERÁRQUICA EM DOIS NÍVEIS...........31

FIGURA 3: ESTRUTURAÇÃO DE REDE DO ANP ............................. 32

FIGURA 4: MÉTODO FUZZY TOPSIS PARA SELEÇÃO DE

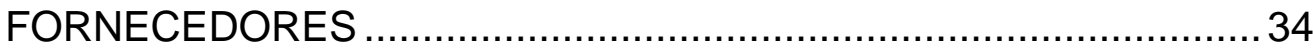

FIGURA 5: NORMALIZAÇÃO DA MATRIZ DE PRIORIDADE .................40 40

FIGURA 6: VETOR DE PRIORIDADE ............................................. 40

FIGURA 7: VALORES OBSERVADOS ........................................... 43

FIGURA 8: VALORES NORMALIZADOS ....................................... 44

FIGURA 9: RANKING DAS ALTERNATIVAS .................................... 44

FIGURA 10: HIERARQUIA MODELO PROPOSTO ............................. 47 


\section{Lista de Tabelas}

TABELA 1: INDICADORES DE DESEMPENHO ATENDIMENTO AO

CLIENTE

TABELA 2: INDICADORES DE DESEMPENHO DO FORNECEDOR... .27

TABELA 3: INDICADORES DE DESEMPENHO GESTÃO DE

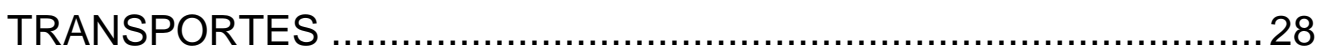

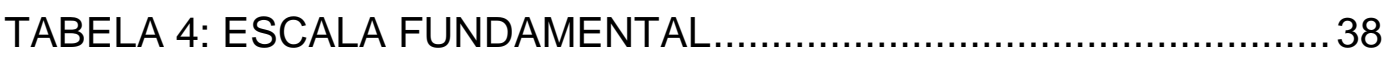

TABELA 5: MATRIZ DE COMPARAÇÃO AHP COM CINCO CRITÉRIOS39

TABELA 6: TABELA PADRÃO PARA CALCULO DE IR.......................... 42

TABELA 7: CARACTERÍSTICAS DOS INDICADORES ..........................52

TABELA 8: COMPARAÇÕES ENTRE CRITÉRIOS................................53

TABELA 9: COMPARAÇÕES INDICADORES PARA O CRITÉRIO GESTÃO 53

TABELA 10: COMPARAÇÕES INDICADORES PARA O CRITÉRIO

QUALIDADE. 54

TABELA 11: COMPARAÇÕES INDICADORES PARA O CRITÉRIO

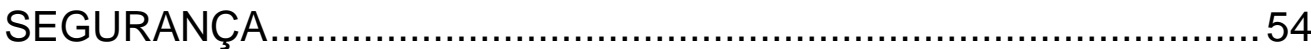

TABELA 12: RESULTADO AVALIAÇÃO PSLS PILOTO - SEGURANÇA56

TABELA 13: RESULTADO AVALIAÇÃO PSLS PILOTO - QUALIDADE . 56

TABELA 14: RESULTADO AVALIAÇÃO PSLS PILOTO - GESTÃO ........57

TABELA 15: RESULTADO AVALIAÇÃO PSLS PILOTO - TODOS

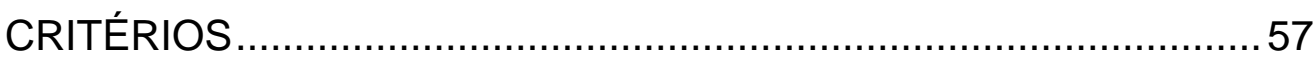

TABELA 16: RANKING DOS PSLS - PILOTO 30 DIAS ...........................58

TABELA 17: COMPARAÇÕES ENTRE CRITÉRIOS GERENTE

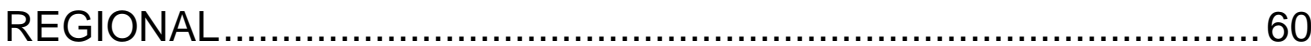

TABELA 18: RANKING DOS PSLS PARA GER. REGIONAL - PILOTO 30 DIAS. 


\section{Introdução}

Com a evolução da tecnologia e seus meios de comunicação, o mundo passou de uma era onde o comércio deixou de ser realizado majoritariamente a nível regional e passou a ser realizado entre empresas em todo o planeta. Esse fenômeno, conhecido como globalização, teve início no final de século XX e início do século XXI, onde houve um crescimento do mercado competitivo com a capacidade de se negociar com países de todo o mundo e exigiu das empresas uma maior capacidade de reestruturação para garantir sua sobrevivência.

Diante deste cenário, as empresas se viram sob a necessidade de aperfeiçoar suas operações e buscar diferencial competitivo, em face de um número de concorrentes cada vez maior. Neste mesmo cenário, a logística deixou de ser vista apenas como uma área operacional das corporações e passou a ser vista como parte estratégica e capaz de trazer vantagem competitiva.

Para Robles e Fischmann (2001), ao final da década de 80, a logística deixa de ser uma parte acessória e torna-se fundamental ao posicionamento estratégico das empresas. Wood Jr (1998) coloca que a logística deixou de ter um enfoque de predominância operacional e passou a ter um papel estratégico nas organizações. Já Tracey (2006) vai além e afirma que a logística influencia o gerenciamento estratégico, a satisfação dos clientes e o desempenho organizacional.

Diante deste cenário extremamente competitivo onde a logística deixou de ser vista como uma atividade operacional e passou a fazer parte da pauta estratégica das empresas, as organizações passaram a buscar práticas capazes de aperfeiçoar suas operações através de reduções de custos, melhorias em sua produtividade e na busca de diferencial competitivo para o mercado. A terceirização de atividade é uma das práticas que se mostrou ser bem sucedida ao longo dos últimos anos, sendo adotada por grande parte das empresas hoje existentes.

A terceirização vai desde atividades que agregam pouco valor ao seu produto final, como segurança patrimonial e limpeza, a atividades complexas 
como as atividades logísticas. A logística, devido à sua importância, não poderia deixar de ser uma das principais áreas de interesse para o processo de terceirização. A terceirização se dá através da contratação de empresas especializadas na execução de atividades logísticas. Essas empresas são chamadas de Prestadores de Serviços Logísticos (PSL). So et al. (2006) descrevem em seu trabalho que a terceirização de atividades logísticas se tornou uma prática comum em muitas empresas.

Em um cenário onde a terceirização logística é crescente e a participação de PSLs em uma atividade considerada estratégica para as empresas, se faz necessário medir o desempenho destes prestadores de serviços de forma a garantir que essa atividade estratégica seja executada de maneira satisfatória. Deste modo, é possível acompanhar o nível de serviço prestado pela empresa contratada e o nível de serviço prestado ao cliente final.

Para Zhang et al. (2007), os indicadores de desempenho tradicionais se mostram ineficientes devido ao ambiente de negócios possuírem muitas incertezas e aspectos intangíveis que precisam ser mensurados. Faz-se necessária a avaliação de desempenho dos prestadores logísticos utilizando aspectos tangíveis e intangíveis e que seja capaz de atribuir pesos para cada indicador, de maneira a se assemelhar com o pensamento da mente humana.

Diante deste cenário, o presente estudo se propõe a desenvolver um modelo de avaliação comparativa de desempenho dos prestadores de serviços logísticos de forma a interpretar a opinião dos tomadores de decisão e que seja possível utilizar indicadores quantitativos e qualitativos. Por se tratar de uma tarefa complexa onde existe uma grande quantidade de indicadores qualitativos e quantitativos para a avaliação dos PSLs, se faz necessária a utilização de técnicas pouco utilizadas no meio organizacional, de maneira a criar um modelo de avaliação comparativa de desempenho que seja capaz de tomar decisão que não seja baseada na intuição dos avaliadores.

Deste modo, através da utilização da técnica de AHP (Analytic Hierarchy Process), desenvolve-se uma ferramenta para avaliação do desempenho dos PSLs de modo a servir de apoio a tomada de decisão no processo de terceirização logística. 


\section{Problema}

Ao longo das últimas décadas as empresas passaram por um amplo processo de terceirização das suas atividades, dentre elas a logística. $\mathrm{O}$ impacto da logística no custo e na qualidade do produto final é notório e amplamente divulgado em diversos estudos apresentados. Silva (2008) destaca em seu trabalho que com a finalidade de obter bons resultados, as empresas precisam de mecanismos capazes de garantir o desempenho das atividades executadas de maneira terceirizada e que estas sejam executadas de maneira integrada e harmoniosa. Novaes (2007) vai além ao afirmar que o insucesso em alguns casos de terceirização de serviços logístico se dá, em parte, a falta de um processo de análise a avaliação dos prestadores de serviços.

Fernandez (2007) destaca em seu trabalho que o processo de medição de desempenho é uma das principais ferramentas de gestão das organizações. Deste modo, na medida em que o processo de terceirização logística se torna cada vez mais frequente e importante na estratégia da empresa, é imprescindível a necessidade de se monitorar e avaliar o desempenho dos prestadores de serviços logístico de forma direcionada aos objetivos maiores das organizações.

O trabalho apresentado foi realizado com a finalidade de preencher essa lacuna existente na maior indústria de gases comerciais e industriais do Brasil presente em todo o território nacional e com operações em todas as regiões do Brasil. Essa lacuna era de um sistema estruturado para avaliação do desempenho de seus prestadores logísticos no mercado de venda de gases através de cilindros de forma a identificar e reconhecer os melhores prestadores de serviço.

Deste modo, o presente estudo busca responder a seguinte pergunta: "de que maneira estruturar um sistema de avaliação comparativa de desempenho dos prestadores logísticos de forma a identificar os melhores prestadores e identificar oportunidade de melhorias?". 


\subsection{Objetivos}

Desenvolver e aplicar um modelo de avaliação comparativa de desempenho logístico, utilizando como base o modelo AHP, de maneira a apoiar o processo de terceirização, identificando oportunidades de melhoria e criando um ranking entre os prestadores de serviço.

\subsubsection{Objetivos Geral}

Desenvolver e aplicar um modelo de avaliação comparativa de desempenho logístico, utilizando como base o modelo AHP, de maneira a apoiar o processo de terceirização, identificando oportunidades de melhoria e criando um ranking entre os prestadores de serviço.

\subsection{Justificativa}

É possível justificar o estudo realizado em função de dois aspectos principais:

Quanto à importância: na medida em que a logística faz parte da pauta estratégica das empresas e a terceirização de atividades logísticas ocorre de forma crescente no mercado, se faz necessário o desenvolvimento de estudos que auxiliem os tomadores de decisão a avaliar o desempenho dos prestadores de serviços logísticos e na tomada de decisão.

Quanto à oportunidade: o fato do autor ser o gestor de transportadores na empresa estudada trouxe agilidade na obtenção dos dados necessários para implementação do modelo proposto. Além disto, se torna mais fácil a obtenção e validação dos resultados alcançados com o estudo junto aos demais envolvidos.

\subsection{Delimitação do Estudo}

O estudo em questão aborda a estruturação de um modelo de avaliação comparativa de desempenho de prestadores de serviço logístico no negócio de gases industriais e medicinais através de cilindros, deste modo, os outros negócios 
da empresa, como a distribuição a granel através caminhões tanque, não estão cobertos pelo estudo apresentado. Este fato se dá porque as demais áreas da empresa estão sob gestão de grupos distintos, o que dificultaria a obtenção dos dados. Além disto, cada área da empresa possui uma característica específica e, com isso, um modelo de avaliação comparativa de desempenho utilizando critérios e atributos únicos não seria capaz de traduzir da melhor maneira a realidade.

Outro ponto de destaque é que somente são avaliados os desempenhos dos transportadores contratados para realizar as entregas e transferências de gases entre unidades, clientes e representantes comerciais, não sendo levados em consideração para esse estudo os prestadores de serviços de armazenagem, distribuição de matéria prima e as demais áreas envolvidas na logística.

A empresa estudada possui mais de cem transportadores atuando na área delimitada acima, desta forma optou-se pela realização de um piloto em uma unidade de negócios representativa e depois por aplicar o estudo apenas para prestadores de serviços logísticos que possuem mais de dois veículos alocados na operação da contratante e, com essa revisão, foram avaliados 41 PSLs.

O modelo proposto busca a avaliação do desempenho dos transportadores contratados, não havendo qualquer julgamento em relação à estratégia utilizada pela empresa para terceirização dos serviços logísticos.

Entende-se que, apesar das delimitações apresentadas acima, o estudo não é inviabilizado, pois atualmente inexiste um sistema de avaliação para tais prestadores de serviço e porque o estudo apresentado poderá servir como base para o desenvolvimento de novos sistemas de avaliação comparativa de desempenho nas mais diferentes áreas das empresas, bem como em outras organizações. 


\section{Metodologia de Pesquisa}

A metodologia utilizada no estudo pode ser dividida nas seguintes etapas:

A. Definição do problema: Nesta etapa foi necessário o levantamento dos principais problemas existentes na empresa e decidido aquele em que um estudo acadêmico seria importante para uma solução baseada experiência de estudiosos da área.

B. Revisão bibliográfica: na seção quatro foi realizada uma ampla revisão bibliográfica, iniciando pela definição dos principais processos abordados no estudo (terceirização, avaliação de desempenho e avaliação de desempenho logístico). Posteriormente foi realizada uma revisão bibliográfica que apresenta os principais métodos de tomada de decisão aplicados recentemente nos trabalho publicados no âmbito acadêmico. Dos métodos estudados, optou-se optou pelo AHP por acreditar que este melhor se aplica ao problema estudado.

C. Detalhamento do modelo estudado: no item 4.4 é detalhado do funcionamento e da implantação do modelo AHP, proposto pelo professor Thomas Saaty em 1990. Utiliza-se um exemplo desde a definição dos critérios que seriam utilizados, passando pelas comparações pareadas dos critérios, cálculo dos vetores de prioridade, conferência da consistência, normalização dos dados até o ranking final com as alternativas do exemplo.

D. Estudo de caso: na seção cinco detalha-se a implantação de um modelo de avaliação comparativa de desempenho na empresa estudada. Nesta seção é detalhado todo o processo que foi utilizado para desenvolvimento do modelo, desde a definição dos critérios e atributos até o resultado final obtido.

E. Avaliação do resultado: na seção seis são apresentados os resultados obtidos, onde é realizada uma avaliação do resultado final do modelo com base na percepção dos tomadores de decisão. 


\section{Revisão Bibliográfica}

\subsection{Terceirização}

Em um mercado cada vez mais competitivo, as empresas vêm buscando ao longo dos últimos anos meios em que possam obter vantagem competitiva, reduzirem seus custos ou melhorar a qualidade de seu produto final. Neste contexto, surge a estratégia de terceirização de atividades, que é o processo de transferência de atividades a fornecedores externos, ou terceiros, onde se estabelece uma relação de parceria de modo que a empresa contratante pode focar seus esforços em tarefas que estão ligadas diretamente a sua atividade fim.

Giosa (1997) define terceirização como um processo de gestão onde algumas atividades são atribuídas a fornecedores terceiros, com os quais se estabelecem uma relação de parceria, permitindo à empresa contratante focar-se na atividade fim e a empresa contratada no negócio onde atua.

Para Queiroz (1995), o início da aplicação da terceirização como é conhecida hoje, deu-se nos Estados Unidos da América da década de 40, quando foram estabelecidas alianças com países europeus para a produção de armamentos, com a finalidade de combater o nazismo alemão. Já no Brasil, o autor destaca que a terceirização começou a ser implantada com a vinda de empresas multinacionais. Ainda segundo o autor, ele acredita que o processo de terceirização ganhou força ao representar uma postura de "ganha-ganha", onde ambas as partes envolvidas tendem a obter vantagens com a parceria.

Segundo Faria (1994), com a terceirização a empresa é capaz de se concentrar em sua atividade fim e, com isso, melhorar a sua produtividade e competitividade, enquanto as empresas terceiras realizam atividades auxiliares ou secundárias nas quais são especializadas, pelo que as realizam de maneira mais racional e com menor custo. Para Sá et al. (1997), a terceirização ganhou uma 
maior importância nos últimos anos em função da necessidade das empresas de racionalizar recursos, redefinir suas operações e funcionar com estruturas cada vez mais enxutas e flexíveis. De acordo com Silva (2005), a terceirização se apresenta como uma possibilidade de decisão adequada a uma série de situações enfrentadas pelas empresas.

Salerno (1993) destaca que a terceirização vem sendo aplicada em três áreas diversas:

- $\quad$ Terceirização da atividade produtiva: quando a empresa deixa de realizar a produção de certos itens e passa a comprá-los de fornecedores;

- $\quad$ Terceirização de atividades de apoio ou auxiliares: quando uma empresa contrata um terceiro para executar atividades que não são objeto fim da empresa ou de apoio a atividade principal. É o caso mais conhecido onde as empresas costumam terceirizar atividades de vigilância, limpeza, jardinagem, manutenção etc.;

- $\quad$ Terceirização de mão-de-obra: onde as empresas contratam uma empresa terceira que aloca mão de obra para executar atividades fim, geralmente esse modelo é utilizado em contratos temporários onde deseja atender a uma demanda pontual.

Em busca de um melhor entendimento do panorama atual da terceirização no Brasil, a figura 1 apresenta o resultado de uma pesquisa realizada pelo Centro Nacional de Modernização através de um trabalho liderado por Giosa (2006). A pesquisa foi realizada em um universo de 2.850 empresas de todas as regiões brasileiras, sendo $92 \%$ delas empresas privadas e $8 \%$ empresas públicas. A amostra de empresas apresenta ainda diferenças relativas à dimensão com empresas de pequeno (5\%), médio (35\%) e grande porte $(60 \%)$. Analisando os dados coletados na pesquisa, podemos destacar os seguintes pontos:

- Dos empresários entrevistados, cerca de 92\% acreditam que o processo de terceirização deve ser utilizado com a finalidade de modernização dos negócios.

$86 \%$ já aplicaram o modelo de terceirização de alguma atividade em sua empresa, seja por iniciativa própria (39\%) ou através de indicação de empresas de consultoria (61\%) 
- Dentre as atividades mais terceirizadas nas empresas, destacam-se as representadas na figura 1 .

Figura 1: Atividades terceirizadas em 2006

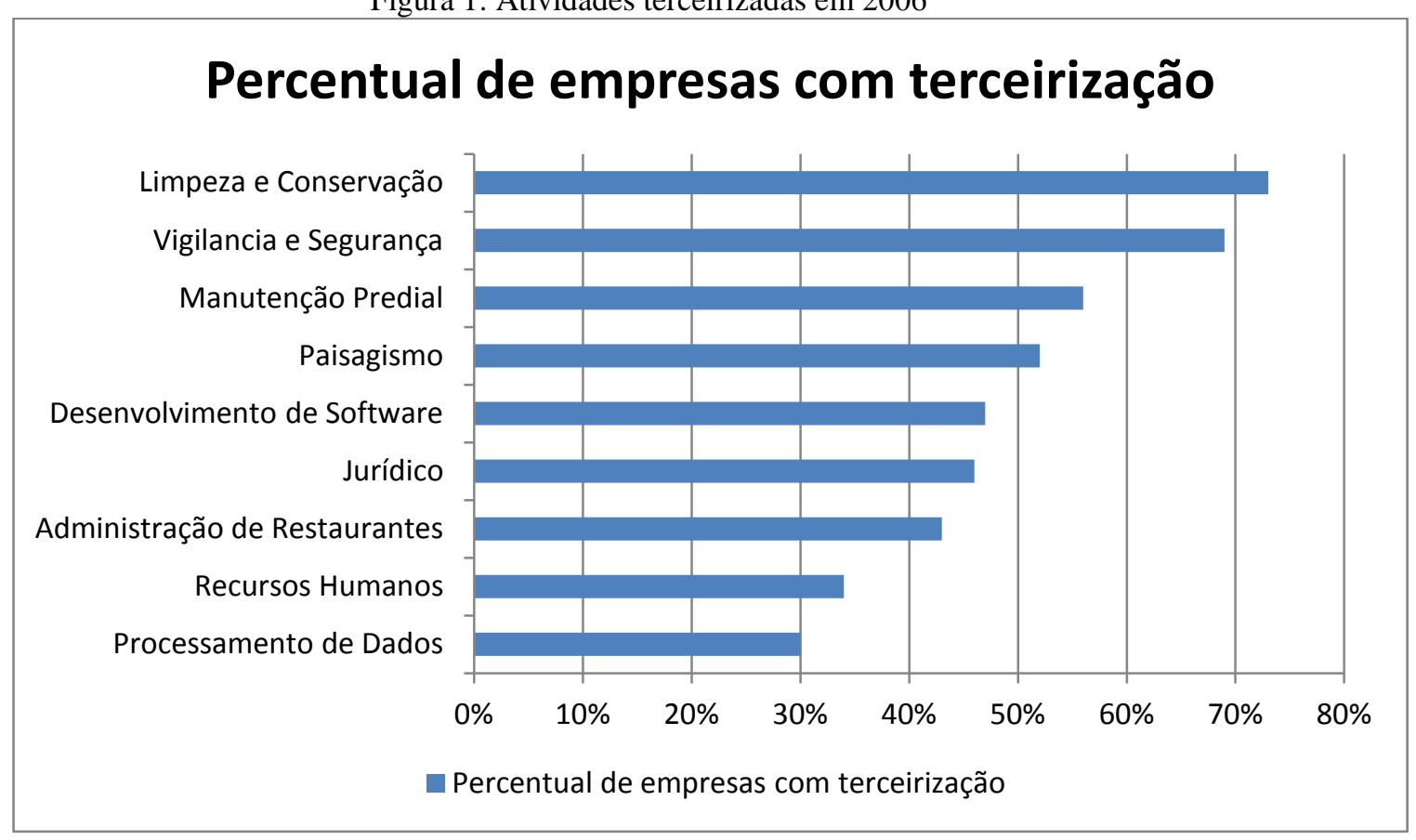

Fonte: Giosa (2006)

Como podemos observar grande parte das empresas consultadas no estudo fizeram a aplicação da terceirização e acreditam que esse processo auxilia as empresas a modernizar seus negócios. O processo de terceirização vem sendo amplamente aplicado em empresas de diferentes tamanhos e, sendo assim, precisamos controlar o desempenho desses fornecedores de maneira a garantir a qualidade do produto final oferecido ao mercado.

\subsection{Avaliação de Desempenho}

Em um ambiente empresarial cada vez mais competitivo, se faz necessária a criação de um método de avaliação e direcionamento de esforços com a finalidade de identificar pontos de melhoria e avaliar o desempenho como um todo. No panorama atual em que empresas multinacionais operam em diversos países e regiões, um modelo de avaliação de desempenho pode auxiliá-las a comparar unidades de negócios semelhantes e a identificar as melhores práticas, 
otimizando a empresa como um todo e facilitando a disseminação do conhecimento.

Fahey (1999) reforça que é necessária a criação de um programa de avaliação que seja capaz de transformar as oportunidades potenciais levantadas em resultados reais. Kaplan e Norton (1997) reforçam a necessidade da criação de um sistema de avaliação de desempenho, pois acreditam que os indicadores financeiros não são mais suficientes para avaliar o desempenho da organização, fazendo-se necessária a criação de um sistema capaz de fornecer informações relevantes ao desempenho de outros aspectos do ambiente corporativo. Duker (2002) reforça também essa visão de que os indicadores exclusivamente financeiros não são mais suficientes. O autor também acredita que as empresas devem buscar criação de valor e não apenas controlar custos. Essa visão não pode ser observada com sistemas tradicionais de indicadores financeiros, sendo necessária a criação de indicadores que avaliem aspectos operacionais.

Segundo DeCenzo e Robbins (2001), o processo de avaliação de desempenho é iniciado com a definição do padrão de desempenho em função dos objetivos estratégicos da organização. Para os autores esses objetivos devem derivar da direção estratégica adotada pela organização.

Para Kaplan e Norton (1997), embora esteja claro que é necessário criar um modelo de avaliação baseado em indicadores de desempenho que traduzam tanto o desempenho financeiro como a performance operacional, não é uma tarefa simples a definição do que deve ser medido e avaliado. Esses indicadores deverão ser selecionados em função da complexidade da operação em questão e deverão estar sempre alinhados com as metas organizacionais. Deste modo, Johnston e Clark (2002) realçam que as informações não devem ser coletadas apenas por serem interessantes ou haver facilidade em obtê-las, mas sim quando se mostram essenciais para os gestores tomarem decisões nos objetivos definidos pela organização.

Parmenter (2002) classifica indicadores de desempenho nas organizações de acordo com a seguinte estrutura hierárquica:

- Indicadores de Desempenho: são obtidos pela união de indicadores chaves de desempenho, ou Key Performance Indicators (KPIs), como quando se pretende apresentar o desempenho de um; 
- Indicadores de Resultado: é a junção de indicadores de desempenho citados no tópico acima, com a finalidade de analisar o resultado da organização ou negócio como um todo. Segundo o autor temos como exemplo de indicadores de resultado: satisfação do cliente, participação no mercado, satisfação de funcionários, lucro líquido, retorno de capital aplicado.

- Indicadores Chave de Desempenho: conhecidos no inglês como Key Performance Indicators (KPIs), são indicadores que são obtidos através de atividades ou processos que são executados pelas empresas.

\subsubsection{Avaliação de Desempenho Logístico}

Como citado anteriormente, ao longo dos últimos anos a logística deixou de ser vista como uma atividade operacional para ser encarada como uma atividade que agrega valor à cadeira. As questões logísticas passaram a integrar as discussões estratégicas da empresa e, com isso, os gestores passaram a despender uma atenção maior em relação ao seu desempenho. Com estratégias cada vez mais agressivas no que tange à cadeia de suprimentos, os gestores dessas áreas passaram a fazer um maior controle dos processos e a acompanhar seu desempenho, buscando garantir o atendimento ao cliente final e o nível de serviço acordado com o cliente.

Diante deste cenário, gestores precisaram criar um sistema para avaliar e acompanhar o desempenho da cadeia de suprimentos, garantindo ao atendimento a sua demanda final. Lima Jr (2001) classifica a evolução do conceito de desempenho logístico em três fases:

- $\quad$ Primeira: considerada pelo autor como "pré-logísitca", a gestão era focada no custo de transporte e administrada de forma independente das demais áreas da organização.

- Segunda: onde se considerou a logística do modo como é conhecida hoje, não apenas o fator de custo de transporte, mas também outros componentes da organização, como estoque e custo de investimento, além de aspectos relacionados com a qualidade do serviço prestado. É nessa fase que os 
trade-offs entre os custos e a qualidade do serviço prestado passou a ser analisados pelos gestores.

Terceira: Fase chamada pelo autor de "neologística", a logística passa a incorporar também outras dimensões da logística, como seu impacto ambiental e social.

Chow (1994) fez uma pesquisa com os principais periódicos sobre logística entre os anos de 1982 e 1992. No qual destaca que existe uma quantidade grande de indicadores logísticos, sendo que nenhum indicador isoladamente é suficiente para medir o desempenho logístico de uma cadeia de suprimentos. Ainda de acordo com o autor, essa grande variedade de indicadores e de estudos voltados ao desempenho logístico se deveu à complexidade do tema e aos diversos autores interessados no tema.

Segundo Holmberg (2000), as empresas ainda utilizam indicadores internos para medir o desempenho das suas atividades logísticas, porém o autor acredita que é necessário utilizar indicadores para toda a cadeia de suprimentos com indicadores internos e externos, de maneira a avaliar o desempenho de toda a cadeia de suprimentos, trabalhando em conjunto para obter um melhor nível de serviço aos clientes. Ainda segundo o autor, outro problema identificado é a falta de consequência entre a estratégia da organização e os indicadores de desempenho que são analisados.

Gunasekaran et al. (2004) destacam em seu artigo que selecionar os indicadores corretos para cada operação e criar um sistema de medição de desempenho não é uma tarefa fácil. $\mathrm{O}$ autor identificou que muitas empresas falharam em utilizar seus sistemas de indicadores de desempenho com a finalidade de obter vantagem competitiva em função da escolha equivocada de indicadores e de sistemas de desempenho.

Krakovics et. al. (2008) destacam em seu trabalho que com o objetivo de se definir indicadores de desempenho é necessário inicialmente estabelecer os objetivos para as medições, como o volume logístico da empresa e a variabilidade dos custos. Para os autores, critérios como simplicidade, confiabilidade e velocidade de obtenção devem ser observados para a definição dos indicadores. Além disso, os autores destacam que qualquer sistema de medição de desempenho deve ainda incluir ao menos um indicador de eficiência, um de atendimento ao cliente e um de capacidade de adequação às mudanças. Os pontos levantados 
pelos autores serão levados em consideração para definição dos indicadores no estudo de caso presente neste trabalho.

Para Handfield e Nichols (1999), as características fundamentais para um sistema de medição de desempenho da cadeia de suprimentos são:

Medir o desempenho da cadeia de suprimentos como um todo e não apenas de processos ou integrantes da cadeia separadamente;

- $\quad$ Ter como objetivo principal o foco no cliente final e a melhoria contínua dos serviços;

- Permitir não apenas a identificação de problemas na cadeia de suprimentos, mas também possibilitar que os gestores eliminem a causa dos problemas operacionais e estratégicos identificados.

Dornier (2000) destaca que a integração e globalização da logística têm grandes impactos sobre a definição e utilização de medidas de desempenho. Para o autor os indicadores logísticos são críticos para uma boa gestão da empresa, pois são fundamentais para a gestão de custos e melhor servir o cliente.

Fleury e Lavalle (2000) acreditam que as empresas estão se conscientizando que não é possível atender as exigências de serviço dos clientes e cumprir os objetivos de custo das empresas sem trabalhar de maneira coordenada com outros participantes da cadeia de suprimentos. Dessa forma, os indicadores de desempenho logísticos podem monitorar a qualidade das atividades logísticas internas e externas (fornecedores e clientes).

Ângelo (2005) destaca que existem diversos processos logísticos dentro das organizações, porém o acompanhamento dos indicadores de todos os processos não é recomendado, pois pode acarretar em uma demora muito elevada para a coleta de dados e dificulta a tomada de decisão em função de informações dispersas.

Segundo Ballou (2001), por ser parte fundamental para o desempenho da organização, os objetivos logísticos devem estar alinhados com a estratégia da organização. Nesse contexto devem ser criados novos processo de controle mantidos os existentes de maneira a comparar o desempenho planejado com o realizado, possibilitando a aplicação de ações corretivas sempre que for necessário aproxima o desempenho real do planejado. 
Com a finalidade de buscar um maior alinhamento entre os objetivos da organização e os objetivos logísticos, Dornier et al. (2000) destacam que os atributos a seguir devem ser observados no momento da seleção de indicadores:

a. Conexão com outros indicadores: Cada indicador deve buscar adicionar informações a dados fornecidos por outros indicadores, desta forma sempre agregando informações e reduzindo a probabilidade de problemas levantados serem esquecidos;

b. Adequação: Os indicadores selecionados devem representar os fenômenos ou processos que se deseja medir;

c. Objetividade: É importante destacar que indicadores não devem julgar o desempenho, mas sim identificar de maneira quantitativa a extensão e direção do problema;

d. Independência: Os indicadores devem ser independente, cada um deve medir determinado aspecto da atividade de logística;

e. Coerência: A definição de um indicador deve ser sempre a mesma tanto no espaço (ex: filiais, regiões, etc.) quanto no tempo;

f. Simplicidade: Quando indicadores requerem raciocínios muito complexos estes têm sua utilidade comprometida;

g. Regularidade: $\mathrm{O}$ resultado dos indicadores deve se manter o mesmo se aplicado exatamente nas mesmas condições, não comprometendo seu resultado em função da época de coleta dos dados para a mesma realidade.

Existem diversos trabalhos na literatura que expõem os mais diferentes tipos de indicadores logísticos, tanto no ambiente interno como no ambiente externo das organizações. Ângelo (2005) destaca em seu trabalho os principais indicadores utilizados na logística de transporte. As tabelas 1, 2 e 3 apresentam esses indicadores, como são calculados e quais são as melhores práticas:

Tabela 1: Indicadores de desempenho atendimento ao cliente

\begin{tabular}{|c|c|c|c|}
\hline \multicolumn{3}{|c|}{ DESEMPENHO NO ATENDIMENTO DO PEDIDO DO CLIENTE } \\
\hline $\begin{array}{c}\text { Indicador de } \\
\text { Desempenho }\end{array}$ & Descrição & Cálculo \\
\hline $\begin{array}{c}\text { Pedido Perfeito ou } \\
\text { Perfect Order } \\
\text { Measurement }\end{array}$ & $\begin{array}{c}\text { Calcula a taxa de pedidos sem } \\
\text { erros em cada estágio do pedido do } \\
\text { Cliente. Deve considerar cada } \\
\text { etapa na "vida" de um pedido. }\end{array}$ & $\begin{array}{c}\% \text { Acuracidade na Separação x \%Entregas no } \\
\text { Prazo x \%Entregas sem Danos x \% Pedidos } \\
\text { Faturados Corretamente }\end{array}$ \\
\end{tabular}




\begin{tabular}{|c|c|c|c|}
\hline $\begin{array}{l}\text { Pedidos Completos e } \\
\text { no Prazo ou \% OTIF } \\
\text { - On Time in Full }\end{array}$ & $\begin{array}{l}\text { Corresponde às entregas realizadas } \\
\text { dentro do prazo e atendendo as } \\
\text { quantidades e especificações do } \\
\text { pedido. }\end{array}$ & $\begin{array}{l}\text { Entregas Perfeitas / Total de Entregas } \\
\text { Realizadas *100 }\end{array}$ & $\begin{array}{l}\text { Para grupos de Clientes A, o índice } \\
\text { varia de } 90 \% \text { a } 95 \% \text {;no geral atinge } \\
\text { valores próximos de } 75 \% .\end{array}$ \\
\hline $\begin{array}{l}\text { Entregas no Prazo ou } \\
\text { On Time Delivery }\end{array}$ & $\begin{array}{l}\text { Desmembramento da OTIF; mede } \\
\% \text { de entregas realizadas no prazo } \\
\text { acordado com o Cliente. }\end{array}$ & $\begin{array}{l}\text { Entregas no prazo / Total de Entregas } \\
\text { Realizadas * } 100\end{array}$ & Variam de $95 \%$ a $98 \%$ \\
\hline $\begin{array}{l}\text { Taxa de Atendimento } \\
\text { do Pedido ou Order } \\
\text { Fill Rate }\end{array}$ & $\begin{array}{c}\text { Desmembramento da OTIF; mede } \\
\% \text { de pedidos atendidos na } \\
\text { quantidade e especificações } \\
\text { solicitadas pelo Cliente. }\end{array}$ & $\begin{array}{l}\text { Pedidos integralmente atendidos / Total de } \\
\text { Pedidos Expedidos * } 100\end{array}$ & 0,995 \\
\hline $\begin{array}{l}\text { Tempo de Ciclo do } \\
\text { Pedido ou Order } \\
\text { Cycle Time }\end{array}$ & $\begin{array}{c}\text { Tempo decorrido entre a } \\
\text { realização do pedido por um } \\
\text { Cliente e a data de entrega. Alguns } \\
\text { consideram como data final a data } \\
\text { de disponibilização do pedido na } \\
\text { doca de expedição. }\end{array}$ & $\begin{array}{l}\text { Data da Entrega menos a Data da Realização do } \\
\text { Pedido }\end{array}$ & $\begin{array}{l}\text { Menos de } 24 \text { horas para localidades } \\
\text { mais próximas ou até um limite de } 350 \\
\mathrm{~km} .\end{array}$ \\
\hline
\end{tabular}

Fonte: Angelo (2005)

\begin{tabular}{|c|c|c|c|}
\hline \multicolumn{4}{|c|}{ DESEMPENHO DO FORNECEDOR } \\
\hline $\begin{array}{l}\text { Indicador de } \\
\text { Desempenho }\end{array}$ & Descrição & Cálculo & Melhores Práticas \\
\hline $\begin{array}{l}\text { tregas realizadas } \\
\text { lentro do prazo } \\
\text { negociado }\end{array}$ & $\begin{array}{l}\text { Calcula a taxa de entregas } \\
\text { realizadas dentro do prazo } \\
\text { negociado com o fornecedor. }\end{array}$ & $\begin{array}{c}\text { Número de entregas realizadas dentro do prazo / } \\
\text { Número de entregas totais }\end{array}$ & \\
\hline $\begin{array}{l}\text { tregas devolvidas } \\
\text { parcial ou } \\
\text { integralmente }\end{array}$ & $\begin{array}{l}\text { Corresponde às entregas de } \\
\text { volvidas parcial ou integralmente } \\
\text { devido à alguma falha não } \\
\text { aceitável do fornecedor. }\end{array}$ & $\begin{array}{c}\text { Entregas devolvidas Parcial ou integralmente / } \\
\text { Total de Entregas recebidas (aceitas }+ \\
\text { devolvidas) }\end{array}$ & \\
\hline $\begin{array}{l}\text { Recebimento de } \\
\text { dutos dentro das } \\
\text { especificações de } \\
\text { qualidade }\end{array}$ & $\begin{array}{l}\text { Corresponde a quantidade de } \\
\text { produtos que foram entregues } \\
\text { dentro das especificações de } \\
\text { qualidade previamente acordadas } \\
\text { com o fornecedor. }\end{array}$ & $\begin{array}{c}\text { Produtos recebidos dentro das especificações de } \\
\text { qualidade acordadas com o fornecedor / Total } \\
\text { de produtos aceitos } * 100\end{array}$ & $\begin{array}{l}\text { Deve ser bem próximo a } 100 \% \text {, caso } \\
\text { contrário, a empresa está aceitando } \\
\text { produtos fora dos padrões desejados } \\
\text { (custos extras) }\end{array}$ \\
\hline $\begin{array}{l}\text { Atendimento do } \\
\text { pedido realizado }\end{array}$ & $\begin{array}{l}\text { Reflete se o fornecedor está } \\
\text { entregando a quantidade de } \\
\text { produtos solicitados }\end{array}$ & $\begin{array}{c}\mathrm{N}^{\circ} \text { produtos entregues } / \mathrm{n}^{\circ} \text { produtos pedidos * } \\
100\end{array}$ & $\begin{array}{l}100 \% \text {. Se este indicador permanecer } \\
\text { por um longo tempo abaixo de } 100 \% \\
\text { significa que o fornecedor não está com } \\
\text { capacidade suficiente para atender os } \\
\text { pedidos. }\end{array}$ \\
\hline $\begin{array}{l}\text { Tempo de entrega } \\
\text { dos produtos }\end{array}$ & $\begin{array}{l}\text { É o tempo que o fornecedor leva } \\
\text { para entregar um pedido. }\end{array}$ & $\begin{array}{c}\text { Data e/ou Hora da realização do pedido ao } \\
\text { fornecedor - Data e/ou Hora da entrega dos } \\
\text { produtos. }\end{array}$ & Varia conforme o negócio da empresa. \\
\hline
\end{tabular}

Fonte: Angelo (2005) 
Tabela 3: Indicadores de desempenho gestão de transportes

\begin{tabular}{|c|c|c|c|}
\hline \multicolumn{4}{|c|}{ DESEMPENHO NA GESTÃO DE TRANSPORTES } \\
\hline $\begin{array}{l}\text { Indicador de } \\
\text { Desempenho }\end{array}$ & Descrição & Cálculo & Melhores Práticas \\
\hline $\begin{array}{l}\text { Coletas no Prazo ou } \\
\text { On Time Pickups }\end{array}$ & $\begin{array}{l}\text { Calcula o \% de coletas realizadas } \\
\text { dentro do prazo acordado. }\end{array}$ & Coletas no prazo / Total de coletas $* 100$ & Variam de $95 \%$ a $98 \%$ \\
\hline $\begin{array}{c}\text { Utilização da } \\
\text { Capacidade de Carga } \\
\text { de Caminhões ou } \\
\text { Truck load Capacity } \\
\text { Utilized }\end{array}$ & $\begin{array}{c}\text { Avalia a utilização da capacidade } \\
\text { de carga dos veículos de transporte } \\
\text { utilizados. }\end{array}$ & $\begin{array}{l}\text { Carga Total Expedida / Capacidade Teórica } \\
\text { Total dos Veículos Utilizados *100 }\end{array}$ & $\begin{array}{l}\text { Depende de diversas variáveis, mas as } \\
\text { melhores práticas estão ao redor de } \\
85 \% .\end{array}$ \\
\hline $\begin{array}{c}\text { Avarias no } \\
\text { Transporte ou } \\
\text { Damages }\end{array}$ & $\begin{array}{l}\text { Mede a participação das avarias } \\
\text { em transporte no total expedido. }\end{array}$ & $\begin{array}{l}\text { Avarias no Transporte }(\mathrm{R} \$) \text { / Total Expedido } \\
\text { (R\$) }\end{array}$ & Variável. \\
\hline $\begin{array}{l}\text { Não Conformidades } \\
\text { em Transportes }\end{array}$ & $\begin{array}{l}\text { Mede a participação do custo extra } \\
\text { de frete de corrente de re-entregas, } \\
\text { devoluções, atrasos, etc por } \\
\text { motivos diversos no custo total de } \\
\text { transporte. }\end{array}$ & $\begin{array}{c}\text { Custo Adicional de Frete com Não } \\
\text { Conformidades (R\$) / Custo Total de Transporte } \\
\text { (R\$) }\end{array}$ & Variável. \\
\hline $\begin{array}{l}\text { Acuracidade no } \\
\text { onhecimento de } \\
\text { :te ou Freight Bill } \\
\text { Accuracy }\end{array}$ & $\begin{array}{l}\text { Mede a participação dos erros } \\
\text { verificados no conhecimento de } \\
\text { frete em relação aos custos totais } \\
\text { de transportes. }\end{array}$ & $\begin{array}{c}\text { Erros na Cobrança (R\$) / Custo Total de } \\
\text { Transporte }(\mathrm{R} \$) * 100\end{array}$ & Mínimo de 98,5 \%. \\
\hline
\end{tabular}

\subsection{Métodos de Tomada de Decisão}

Processos de tomada de decisão baseados na intuição e experiência dos avaliadores podem levar a erros na hora de determinar a melhor solução dentre as diversas opções existentes. Atualmente vivemos em um ambiente que estamos constantemente tomando decisões, seja no ambiente corporativo ou na vida pessoal. Como exemplo, temos a decisão de qual carro comprar dentre as diversas opções existentes no mercado. Esse processo decisório envolve uma grande quantidade de indicadores e, com isso, dificulta a definição da melhor alternativa.

Meyer (2003) destaca que a quantidade de variáveis objetivas e subjetivas para a tomada de decisão é enorme e que a simplificação da solução do problema de decisão é a melhor solução. $\mathrm{O}$ autor defende que as medidas não são perfeitas e não é necessário medir o todo, mas sim encontrar quais variáveis realmente importam e conduzem a um plano de ação eficiente.

Liedtka (2005) defende ainda que não basta apenas selecionar as variáveis que melhor conduzem ao objetivo da organização. Para o autor, a falta de um 
sistema estruturado de apoio à tomada de decisão torna essa tarefa extremamente difícil e sujeita a erros na busca da solução ótima.

Para Rafaeli (2009), a formulação de uma estrutura de pensamento multicritérios auxilia o tomador de decisão em seu processo decisório. Porém, Bernroider e Stix (2007) já destacavam em seu trabalho que, apesar da análise da decisão ser reconhecidamente uma ferramenta importante de avaliação para decisões importantes, as empresas ainda não utilizavam metodologias multicritérios para a tomada de decisão. Santos (2000) destaca que o tomador de decisão necessita de informações relevantes ao problema, mas antes de tudo precisa de um dispositivo que o auxilie à decisão, pois o mesmo estará exposto a uma quantidade infinita de informações. Por isso, um sistema estruturado de apoio a decisão auxilia a busca das informações que são relevantes ao processo decisório, simplificando a tarefa.

\subsubsection{Técnicas de Tomada de Decisão}

Como exposto na seção anterior, a grande maioria dos processos de tomada de decisão nas organizações requer uma análise simultânea de mais de um atributo. Esse tipo de escolha, onde mais de um aspecto deve ser considerado, é chamado na literatura por decisões de múltiplos critérios, multiatributos ou multiobjectivo.

Gomes (2007) já reforçava em seu trabalho que as análises multicritérios são bem adequadas, pois tornam o processo decisório mais claro e trazem mais credibilidade ao basear seu resultado nas preferências expressas pelos tomadores de decisão na formulação do método.

Existem diversas técnicas para auxílio à tomada de decisão, no que diz respeito à avaliação de fornecedor. Diversos trabalhos foram publicados ao longo dos últimos anos. Esses trabalhos trazem diferentes técnicas para tratar o caso, cada uma com a sua particularidade.

A seguir, será realizada uma breve descrição das principais técnicas de apoio a tomada de decisão que julgamos serem adequados para implantação de um sistema de avaliação comparativa de desempenho de transportadores 
logísticos. Não serão abordadas todas as técnicas existentes, mas sim as mais adequadas ao problema que será estudado:

- $\quad$ Ponderação de Fatores (por scores ou ranking): Muito utilizado nas organizações, esse método tradicionalmente utiliza mais de um critério para sua avaliação. É atribuído um peso para cada critério ou indicador, são criadas faixas de controle onde cada faixa recebe uma pontuação e através da soma da pontuação de todos os critérios é criado um ranking. Apesar de ser amplamente aplicado em diversas organizações, esse método tende a ser impreciso, pois a definição dos pesos e faixas de controle é feita de maneira não-estruturada pelo tomador de decisão, podendo levar a uma decisão que não seja a mais otimizada possível. Dentro deste escopo, Klapan e Norton (1997) desenvolveram um método chamado de Balance Score Card (BSC) para avaliação de desempenho focada em critérios não apenas financeiros, mas sim levando em consideração quatro perspectivas (financeiros, processos internos, clientes e aprendizagem).

AHP (Analytic Hierarchy Process): Gomes (2007) destaca que o AHP foi um dos primeiros métodos desenvolvidos para a tomada de decisão baseado em múltiplos critérios. O método utiliza um processo estruturado para solucionar problemas complexos que podem ter critérios quantitativos e qualitativos. Utilizando a comparação dois a dois em uma escala de um a nove, o método auxilia o tomador de decisão a especificar suas preferências e definir pesos, auxiliando no processo de decisão de forma objetiva. A figura abaixo representa a estrutura de decomposição de uma meta ou objetivo em critérios e alternativas propostas por Saaty (1990): 
Figura 2: Estruturação hierárquica em dois níveis

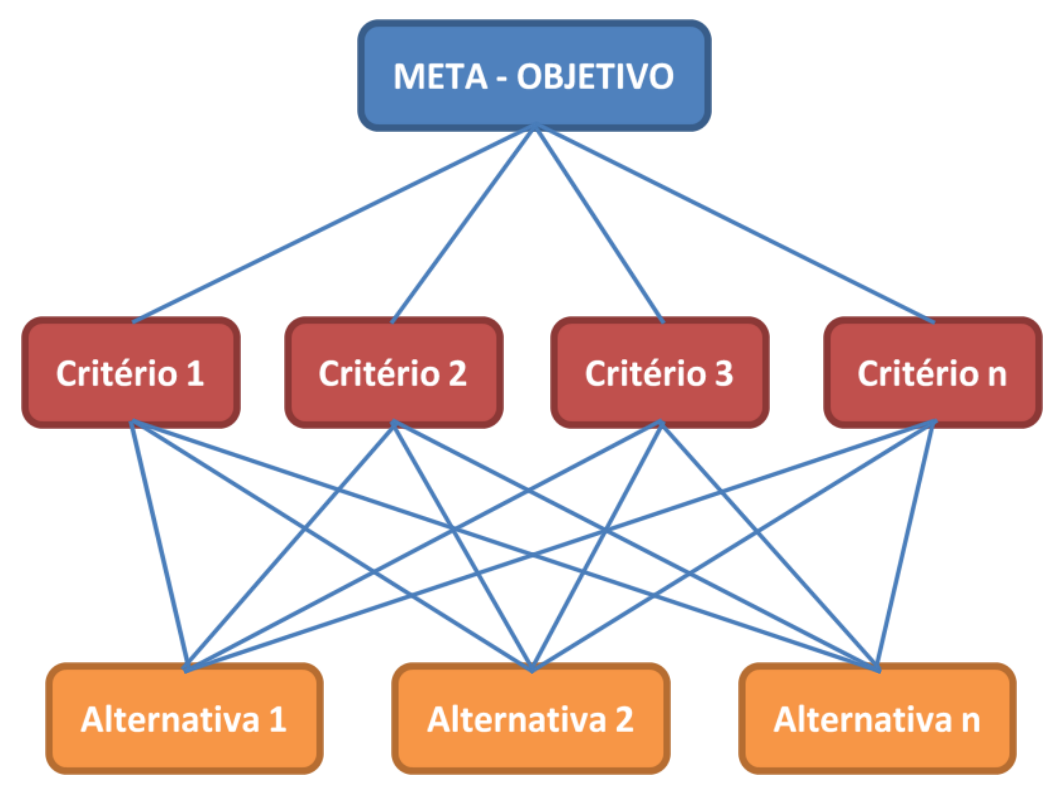

Fonte: modificado de Saaty (1991)

O método foi apresentado por Saaty (1991) e, para o autor, ele é fundamentado na estruturação de forma hierárquica e na comparação em pares de cada um dos seus fatores, sendo fiel a situações de vida reais uma vez que analisa os elementos mais importantes e a relação entres os diferentes elementos. Trata-se de um método bastante difundido e com diversas publicações no ambiente acadêmico e profissional, diversos trabalhos apresentados no ramo de avaliação e seleção de prestadoras de serviços logísticos.

- $\quad$ ANP (Analytic Network Process): Também desenvolvido por Thomas L. Saaty, o ANP é uma forma genérica do AHP, sendo um método de apoio à decisão também baseado em multicritérios. Enquanto o AHP tem sua estrutura através da decomposição de um objetivo em critérios e alternativas de maneira hierárquica, o ANP tem sua estrutura baseada em uma rede de nós. Enquanto existirem relações entre esses nós, eles são comparados dois a dois, incorporando as relações de interdependência entre critérios e alternativas. Tal como no AHP, o processo utiliza uma matriz para representação e comparação dos pares da rede. Segundo Saaty (1999), o ANP representa o efeito de dependência e feedback dentro e entre os conjuntos de elementos avaliados: 
Figura 3: Estruturação de rede do ANP

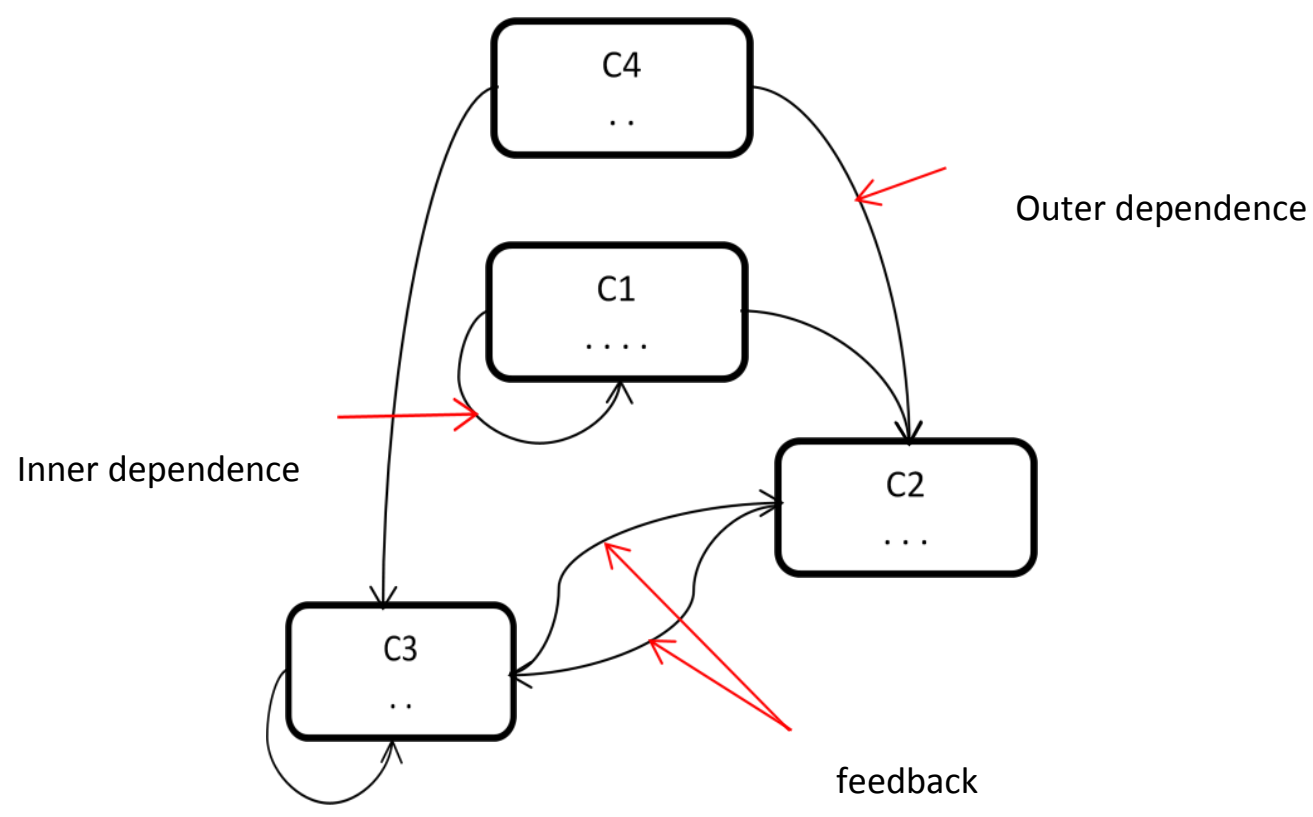

Fonte: Saaty (2005)

Assim como o AHP, o ANP é bastante utilizado em estudos para seleção e avaliação de fornecedores, Cheng e Lee (2010) em seu trabalho apresentam a utilização do ANP para seleção de fornecedores para logística reversa do setor de televisores de cristal líquido (LCD) em Taiwan. Sarkis e Talluri (2002) sugerem um modelo para seleção e avaliação através da utilização do método ANP em um caso empírico, no qual sete critérios que são distribuídos em dois conjuntos (clusters) e duas alternativas de decisão.

- DEA (Data Envelopment Analysis): Proposto por Charnes et al. (1978) e tendo como base os estudos sobre eficiência elaborados por Debreu (1951), Koopmans (1951) e Farrel (1957), é um modelo baseado em programação linear que utiliza o conceito de eficiência, dado um conjunto de recursos (input) e resultados (output). Macedo (2009) destaca que o modelo utiliza o conceito de quanto menor o valor dos inputs, melhor e quanto maior os outputs melhor. $\mathrm{O}$ modelo utiliza unidades de tomada de decisão (DMUs - Decision Making Unit) 
que podem ser empresas, unidades de negócio, cidades ou qualquer outra unidade homogênea que se deseja comparar. Para Charnes et al. (1978), o modelo propõe uma técnica para mensurar qualquer DMU através da busca do máximo de resultados (outputs) e o mínimo de recursos ponderados (inputs). Weber et al. (1998) definem Análise de Envoltórios de Dados (DEA) como um método de programação matemática que auxilia a tomada de decisão com base em múltiplos parâmetros, permitindo escolher a melhor opção e, consequentemente, reduzir os custos de aquisição. Como enfatizado por Sinuany-Stern et al. (2000), a DEA em seu formato original não gera uma classificação dos DMUs, mas os classifica entre os grupos de unidades eficientes e ineficientes, por esse motivo, Seydel (2006) destaca que essa técnica não é geralmente utilizada para seleção da melhor alternativa ou criação de ranking de alternativas, embora - segundo o autor existe grande capacidade para isso.

- FuzzyLogic (lógica difusa): De acordo com Laudon e Laudon (2000), a lógica é uma técnica que nos permite a tomada de decisão a partir de conhecimentos imprecisos e incompletos ou até que possuam dados ambíguos. Vaclavik (2011) destaca que a mente humana tende a pensar em termos relativos e não absolutos, dessa forma para a autora, a lógica difusa permite solucionar problemas através da computação que são capazes de simular o pensamento da mente humana, onde as variáveis de decisão não se limitam a "sim" ou "não", sendo possível a programação utilizando respostas mais abstratas como "talvez" ou "um pouco menos". Carvalho et al. (1998) apresentam um trabalho onde utiliza o fuzzy logic através do desenvolvimento de um sistema computacional para classificação de fornecedores em função de quatro critérios principais. Santi et al. (2011) utilizam uma combinação de lógica difusa, teoria de decisão multi-atributo para selecionar fornecedores de forma a minimizar o custo total, o prazo de entrega e maximizar o desempenho médio do fornecedor.

\section{- $\quad$ TOPSIS (Technique for Order Preference by Similarity to Ideal} Solution); é uma técnica apresentada por Liu e Wang (2009) que visa avaliar o desempenho das alternativas possíveis através da similaridade com a solução ideal. O método utiliza uma estrutura pré-definida para encontrar a melhor solução ideal positiva e a mais distante da solução ideal negativa. A solução ideal 
positiva consiste na solução que maximiza os critérios de benefício e minimiza os critérios de custo, por outro lado, a solução ideal negativa maximiza o custo e minimiza os critérios de benefício. Na figura 4 podemos observar a estrutura simplificada de aplicação do método:

Figura 4: Método fuzzy TOPSIS para seleção de fornecedores

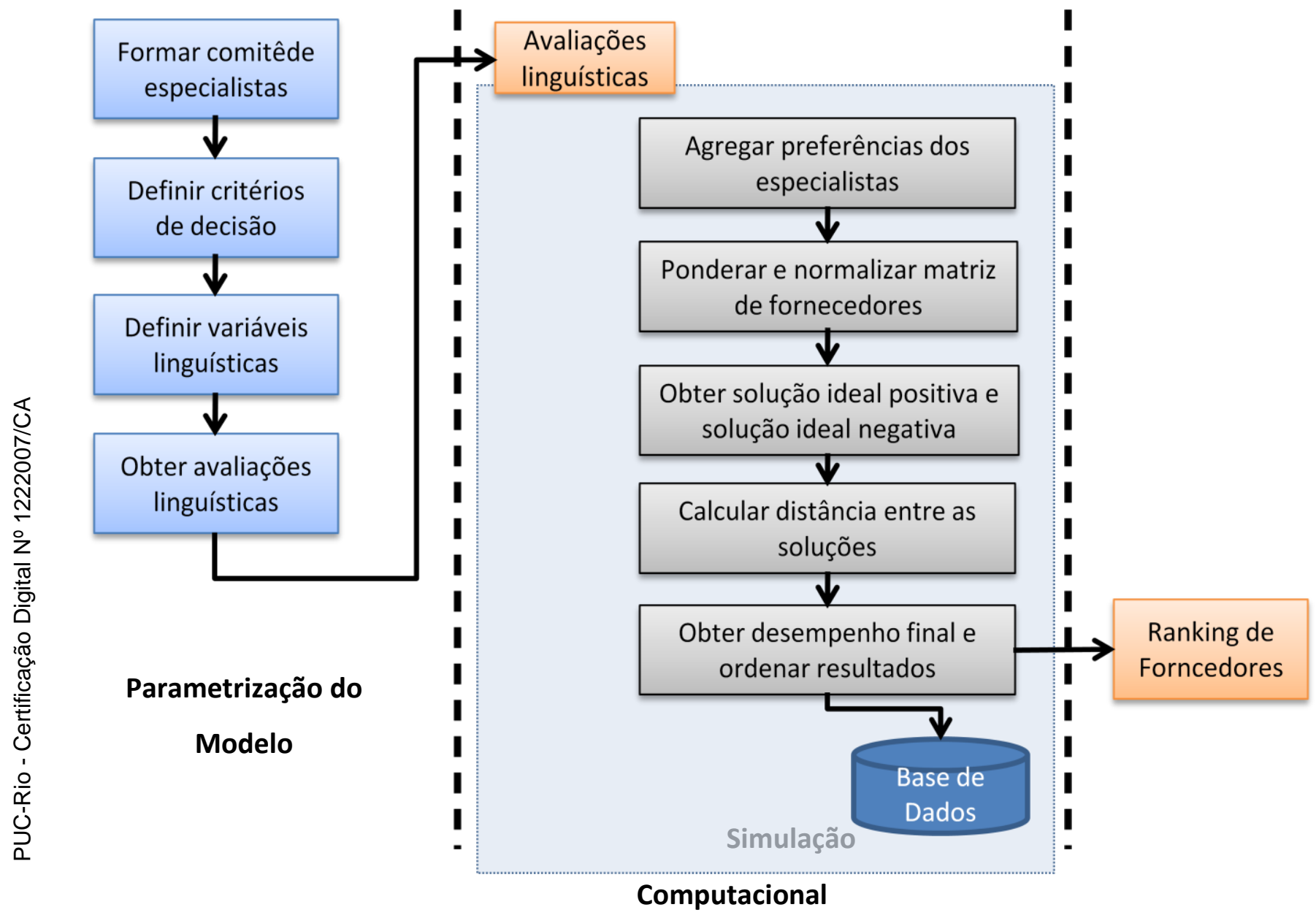

Fonte: Lima Jr (2013)

Existem na literatura diversos trabalhos apresentados na seleção de fornecedores, mas não foi encontrado nenhum trabalho que utilize o método para avaliação de desempenho de fornecedores utilizando indicadores qualitativos e quantitativos.

\section{- $\quad$ PROMETHEE (Preference Ranking Organization Method for}

Enrichment Evaluation): Teve sua primeira apresentação por Brans (1982) e 
Segundo Vincke (1992), o método consiste na construção de uma relação sobre classificação valorada e que possui conceitos físicos e econômicos que são facilmente entendidos pelos tomadores de decisão. Brans et al. (1984) destacam que pequenos desvios nos valores dos parâmetros do método não afetam o resultado final do ranking, por isso os autores acreditam que os principais benefícios são: simplicidade, clareza e estabilidade e robustez. Em trabalho publicado posteriormente Brans e Vincke (1985) reforçam, como principal vantagem do modelo, a facilidade de entendimento pelos tomadores de decisão. Segundo Scharling (1996) e Vincke (1989), o PROMETHEE se trata de um método de subordinação, que busca construir uma relação de superação entre as alternativas. Como ponto fraco identificado na literatura, temos o fato do decisor atribuir pesos aos critérios selecionados sem utilizar um método estruturado. Desta forma, o resultado final pode ser distorcido em função de uma má definição dos pesos pelo tomador de decisão. Araujo (2012) utiliza a técnica para criação de um modelo seleção e avaliação de desempenho de fornecedores, o qual foi aplicado com sucesso em uma indústria de alimentos. Pereira (2003) apresenta um trabalho onde demonstra um modelo baseado em PROMETHEE implementado para seleção de uma prestadora de serviço de desenvolvimento de software para a indústria de peças automotivas.

\subsubsection{Justificativa do Método Escolhido}

Após a revisão da bibliografia realizada, onde foram analisadas diferentes técnicas de apoio a tomada de decisão na área de seleção e avaliação de fornecedores e com base nos resultados apresentados na literatura com a aplicação de cada um, optou-se por utilizar o método AHP (Analytic Hierarchy Process) em função dos motivos que podemos destacar abaixo:

- É Um método amplamente divulgado e aplicado na literatura, especificamente na área de seleção e avaliação de prestadores de serviços logísticos;

Ao comparar a técnica com o ANP, identificou-se que o AHP melhor se aplica, pois o caso estudado não possui interdependência entre fatores, sendo mais bem aplicada uma técnica de hierarquia. Além deste fator, identificou- 
se que o ANP é pouco utilizado para análise operacional do desempenho de fornecedores, mas sim em trabalhos que visam de uma forma mais estratégica a seleção de novos fornecedores;

Em relação à aplicação do modelo DEA ao estudo de caso proposto, destaca-se que o objeto do estudo é criar um modelo para avaliação de desempenho de transportadores que já prestam serviço. Cada um possui seu tamanho de operação, e região de atuação. $O$ foco do trabalho não é avaliar o transportador que produz o máximo de benefícios através do mínimo de inputs, mas sim classificar o transportador em função de seu desempenho na prestação de serviço, tanto com critérios quantitativos como qualitativos;

Em relação aos modelos de pontuação através de ranking, entendese que esses modelos são pouco estruturados e muito baseados no conhecimento e sentimento do tomador de decisão. Dessa forma, esse tipo de modelo pode não ser fiel à realidade no que tange a avaliação de desempenho de fornecedores;

Através de formulação matemática, o modelo busca a consistência das respostas da matriz de prioridades criada pelo tomador de decisão. Desta forma, o AHP busca traduzir as prioridades do decisor de maneira que o resultado da avaliação seja fidedigno com a realidade encontrada.

- $\quad$ Outros modelos onde é utilizada a combinação de mais de uma técnica identificou-se que existe uma maior complexidade para implantação da ferramenta e, na literatura, esses modelos são propostos para problemas mais complexos, aonde os fatores possuem interdependência e subjetividade, o que não é o caso para o modelo proposto.

De forma geral, foi observada com a revisão bibliográfica a utilização de diversos modelos para a avaliação de desempenho logístico. Porém, entende-se que existe uma vasta quantidade de trabalhos que utilizam o método AHP por trazer resultados objetivos, precisos e por ser um método bem estruturado com fácil implementação no ambiente corporativo. Colin (2007) destaca em seu trabalho que o AHP deve ser entendido como um processo em que estrutura o pensamento para a tomada de decisão, e não um algoritmo que busca a solução do problema apresentado. 
Portanto, após revisão bibliográfica dos principais métodos de auxilio à tomada de decisão, será utilizado o AHP para formulação do modelo de apoio a tomada de decisão baseado no desempenho dos transportadores.

\subsection{Método AHP}

O método AHP foi proposto pelo professor Thomas Saaty e teve origem no início da década de 70 quando o mesmo começou a questionar de que maneira as pessoas processavam informações necessárias para a tomada de decisão em suas mentes e de que modo expressavam seu julgamento. Com esse intuito, iniciou-se o desenvolvimento de um modelo onde são consideradas hierarquias e redes, comparações dois a dois, escalas proporcionais, consistência, prioridade, entre outros fatores. Com base nesse pensamento, foi estruturado o modelo conhecido como AHP (Analytic Hierarchy Process por Saaty, 1991).

Saaty (1991) afirma que o método trabalha de maneira semelhante à mente humana, ou seja, ao se deparar com um grande número de elementos, a mente busca consolidá-los em grupos comuns, repetindo o processo para agregação em grupos superiores até chegar ao objetivo central do problema. Além disto, o autor destaca em seu trabalho que uma das etapas mais importantes no processo de tomada de decisão é a seleção dos fatores que são importantes e devem ser considerados.

O AHP é fundamentado de maneira a hierarquizar esses fatores, passando do objetivo principal, pelos critérios, atributos e alternativas, assim reproduzindo de modo semelhante ao funcionamento da mente humana.

Uma vez finalizada a hierarquia, é necessário identificar a importância relativa dos elementos de cada um desses níveis. Elementos no mesmo nível hierárquico são comparados dois a dois em relação a sua influência ao elemento posicionado no nível superior. Para realizar essa comparação de dominância, Saaty (1991) sugere uma escala de 1 a 9 que é apresentada na tabela 4. 
Tabela 4: Escala fundamental

\begin{tabular}{|c|c|c|}
\hline Índice & Definição & Descrição \\
\hline 1 & Igual importância & $\begin{array}{c}\text { Os dois elementos contribuem } \\
\text { igualmente para o objetivo }\end{array}$ \\
\hline 3 & Importância pequena de uma para outra & $\begin{array}{l}\text { A experiência do avaliador diz que um } \\
\text { elemento possui importância pouco } \\
\text { maior que o outro para o objetivo }\end{array}$ \\
\hline 5 & Importância grande & $\begin{array}{l}\text { A experiência do avaliador diz que um } \\
\text { elemento possui importância maior que } \\
\text { o outro para o objetivo }\end{array}$ \\
\hline 7 & Importância muito grande & $\begin{array}{l}\text { A experiência do avaliador diz que um } \\
\text { elemento possui importância } \\
\text { relativamente maior que o outro para o } \\
\text { objetivo }\end{array}$ \\
\hline 9 & Importância absoluta & $\begin{array}{l}\text { A experiência do avaliador diz com alto } \\
\text { grau de certeza que um elemento } \\
\text { possui importância maior que o outro } \\
\text { em relação ao objetivo }\end{array}$ \\
\hline $2,4,6,8$ & Valores intermediários & $\begin{array}{l}\text { Utilizado quando é necessário um índice } \\
\text { intermediário de importância }\end{array}$ \\
\hline
\end{tabular}

Fonte: modificado de Saaty (1990)

Utilizando a tabela acima, quando dois elementos, um da linha m e outro da coluna n são comparados pelo tomador de decisão, o valor 1 representa uma situação onde não existe diferença entre $m$ e $n$. Porém, quando m é extremamente mais importante/preferido em relação à n, o valor 9 é utilizado. Por outro lado, se o oposto for verdadeiro, o valor 1/9 é utilizado.

Entani (2001) destaca em seu trabalho que o AHP é capaz de considerar diversos fatores com diferentes graus de importância. Porém, a tarefa de atribuir o grau de dominância na comparação dois a dois não é uma tarefa simples para o tomador de decisão e, se não for bem executada, pode resultar em um modelo de avaliação falho.

Após as comparações pareadas através da hierarquia previamente criada e a tabela fundamental desenvolvida por Saaty (1991), cria-se uma matriz quadrada onde, por convenção, são apresentados os resultados das comparações entre o 
elemento que consta na coluna da esquerda na linha com o elemento que é apresentado na primeira linha da coluna de comparação.

A tabela 5 apresenta um exemplo de matriz de julgamentos utilizada no método AHP. No exemplo em questão, são comparados aos pares um total de cinco critérios.

Tabela 5: Matriz de comparação AHP com cinco critérios

$\left[\begin{array}{cccccc} & & & & & \\ \mathrm{A} & \mathrm{A} & \mathrm{B} & \mathrm{C} & \mathrm{D} & \mathrm{E} \\ \mathrm{B} & 1 & 3 & 1 / 9 & 1 / 5 & 5 \\ \mathrm{C} & 1 / 3 & 1 & 1 / 9 & 1 / 7 & 1 \\ \mathrm{D} & 9 & 9 & 1 & 3 & 7 \\ \mathrm{E} & 5 & 1 / 3 & 1 / 3 & 1 & 9 \\ & 1 / 5 & 1 & 1 / 7 & 1 / 9 & 1\end{array}\right]$

Fonte: elaborado pelo autor

Repare que, no exemplo da tabela 5, os valores que constam na diagonal que começa na comparação entre o par AA sempre possuem valores iguais a um. Isso se dá porque quando comparado com ele próprio o elemento tem importância igual. Para o preenchimento das demais comparações, é utilizada a escala apresentada na tabela 4 proposta por Saaty (1991). Reparem ainda que o resultado da comparação do item A com o item $\mathrm{C}$ é o inverso da comparação do item $\mathrm{C}$ em relação ao item A, ou seja, se A tem seu valor igual a 1/9 quando comparado com $\mathrm{C}$, então $\mathrm{C}$ deve ter seu valor igual a 9 quando comparado com A. Isso ocorre porque o método utiliza o conceito de reciprocidade, onde as comparações entre os pares é realizada apenas uma vez. Este conceito é uma evolução ao modelo inicial proposto por Saaty (1991) que busca uma maior facilidade de implementação do AHP, reduzindo as chances de ocorrerem inconsistências.

Ainda segundo Saaty (1991), após o preenchimento de toda a matriz de comparações, são associados à matriz os seus autovetores (que definem a prioridade de julgamento) e seu autovalor (que define a consistência dos valores apresentados).

Para que sejam calculados os autovetores, é necessário que seja encontrado o vetor de prioridade da matriz, através da soma de todos os componentes das 
colunas e dividindo cada componente por essa soma. Esse processo, também chamado de normalização, está ilustrado na Figura 5 utilizando como base a matriz existente na tabela 5 .

Figura 5: Normalização da matriz de prioridade

\begin{tabular}{c|ccccc} 
Critérios & A & B & C & D & E \\
A & 0,06 & 0,21 & 0,07 & 0,04 & 0,22 \\
B & 0,02 & 0,07 & 0,07 & 0,03 & 0,04 \\
C & 0,58 & 0,63 & 0,59 & 0,67 & 0,30 \\
D & 0,32 & 0,02 & 0,20 & 0,22 & 0,39 \\
E & 0,01 & 0,07 & 0,08 & 0,02 & 0,04 \\
Totais & 1,00 & 1,00 & 1,00 & 1,00 & 1,00
\end{tabular}

Fonte: elaborado pelo autor

Após a normalização, é necessário calcular a média dos valores normalizados para que seja calculado o vetor de prioridade de cada critério. A Figura 6 ilustra esse cálculo utilizando o exemplo da tabela 5.

Figura 6: Vetor de Prioridade

$\begin{array}{ccccccr}\text { Critérios } & \text { A } & \text { B } & \text { C } & \text { D } & \text { E } & \begin{array}{c}\text { Vetor } \\ \text { Prioridade }\end{array} \\ \text { A } & 0,06 & 0,21 & 0,07 & 0,04 & 0,22 & 0,12 \\ \text { B } & 0,02 & 0,07 & 0,07 & 0,03 & 0,04 & 0,05 \\ \text { C } & 0,58 & 0,63 & 0,59 & 0,67 & 0,30 & 0,55 \\ \text { D } & 0,32 & 0,02 & 0,20 & 0,22 & 0,39 & 0,23 \\ \text { E } & 0,01 & 0,07 & 0,08 & 0,02 & 0,04 & 0,05 \\ \text { Totais } & 1,00 & 1,00 & 1,00 & 1,00 & 1,00 & 1,00\end{array}$

Fonte: elaborado pelo autor

Observe que o critério $\mathrm{C}$ é o que possui o maior vetor de prioridade e, de acordo com a avaliação dos tomadores de decisão, seu resultado deverá ser o que mais impacta o objetivo central. O próximo passo é a realização do teste de consistência das respostas dadas pelos decisores, buscando identificar se as respostas estão logicamente relacionadas.

Saaty (1991) propõe o seguinte procedimento para o teste de consistência: 
1. Multiplicar a matriz das comparações pelo vetor de prioridade, obtendo um novo valor, dividindo o primeiro componente deste vetor pelo primeiro componente do vetor de prioridade calculado anteriormente, o segundo componente do vetor pelo segundo componente do vetor de prioridade e assim por diante. No exemplo adotado nas figuras 4 e 5 e na tabela 5 teríamos o seguinte valor:
A: $[0,12 * 1+0,5 * 3+0,55 * 0,11+0,23 * 0,20+0,05 * 5] / 0,12=5,01$
B: $[0,12 * 0,33+0,05 * 1+0,55 * 0,11+0,23 * 0,14+0,05 * 1] / 0,05=4,92$
C: $[0,12 * 9+0,05 * 9+0,55 * 1+0,23 * 3+0,05 * 7] / 0,55=5,55$
D: $[0,12 * 5+0,05 * 0,33+0,55 * 0,33+0,23 * 1+0,05 * 9] / 0,23=6,29$
E: $[0,12 * 0,2+0,05 * 1+0,55 * 0,14+0,23 * 0,11+0,05 * 1] / 0,05=4,73$

Considerando equação (1), onde:

$$
\mathrm{Ax}=\lambda_{\max } \mathrm{X}
$$

A é a comparação da matriz $n \times n$, para $n$ critérios, também chamada de matriz de prioridade.

$$
\begin{aligned}
& \mathrm{x} \text { é o autovetor de tamanho } \mathrm{n} \times 1 \text {, também chamado de vetor de prioridade. } \\
& \lambda \text { max é } \mathrm{p} \text { autovalor }
\end{aligned}
$$

2. Dividir a soma dos valores calculados neste novo vetor pelo número de componentes, chegando assim a uma aproximação do valor do autovalor máximo $(\lambda \max )$. Quando mais próximo o autovalor máximo for do número de componentes, mais consistente é o resultado obtido. No exemplo em questão temos:

$$
(5,01+4,92+5,55+6,29+4,73) / 5=5,30
$$

O autovalor $(\lambda \max )$ é obtido através da equação (2):

$$
\lambda \max =\frac{1}{n} \sum_{i=1}^{n} \frac{[A \bar{w}] i}{\bar{w} i}
$$


3. Calcula-se o índice de consistência utilizando a equação (3), também conhecida como desvio de consistência.

$$
I C=\frac{\lambda \max -\mathrm{n}}{(n-1)}
$$

Aplicando a formula ao exemplo temos: $\mathrm{IC}=(5,30-5) / 4=0,08$

Onde, $\lambda$ max é o autovalor máximo e n o número de alternativas.

4. Utilizando-se a tabela 6 proposta por Saaty (1991) é obtido o índice randômico padrão em função do número de alternativas:

Tabela 6: Tabela padrão para calculo de IR

\begin{tabular}{|c|c|c|c|c|c|c|c|c|c|c|c|c|c|c|c|}
\hline $\begin{array}{l}\text { úmero de } \\
\text { rnativas }(\mathrm{n})\end{array}$ & 1 & 2 & 3 & 4 & 5 & 6 & 7 & 8 & 9 & 10 & 11 & 12 & 13 & 14 & 15 \\
\hline $\mathrm{IR}$ & 0,00 & 0,00 & 0,58 & 0,90 & 1,12 & 1,24 & 1,32 & 1,41 & 1,45 & 1,49 & 1,51 & 1,48 & 1,56 & 1,57 & 1,59 \\
\hline
\end{tabular}

Fonte: Saaty (1991)

Utilizando o exemplo em questão, temos: $\mathrm{IR}=1,12$

5. Por fim, calculando a razão entre o índice de consistência (IC) e o índice randômico (IR) de mesma razão, temos a razão de consistência (RC). São consideráveis aceitáveis matrizes que possuem a razão de consistência inferior a 0,10 . Isto dito, temos o seguinte resultado no exemplo apresentado:

$$
R C=\frac{I C}{I R} \quad \rightarrow \quad R C=\frac{0,08}{1,12}=0,07
$$

Desta forma, no exemplo utilizado, podemos aceitar a matriz paritária, pois a sua razão de consistência (RC) é inferior a 0,10 não sendo necessário reformular a matriz.

Por fim, deve ser realizado o score geral para cada alternativa onde, utilizando os vetores de prioridade obtidos nos passos anteriores e utilizando os 
valores reais encontrados para cada alternativa. Na figura 7 apresentamos valores encontrados para o exemplo utilizado nesta seção:

Figura 7: Valores observados

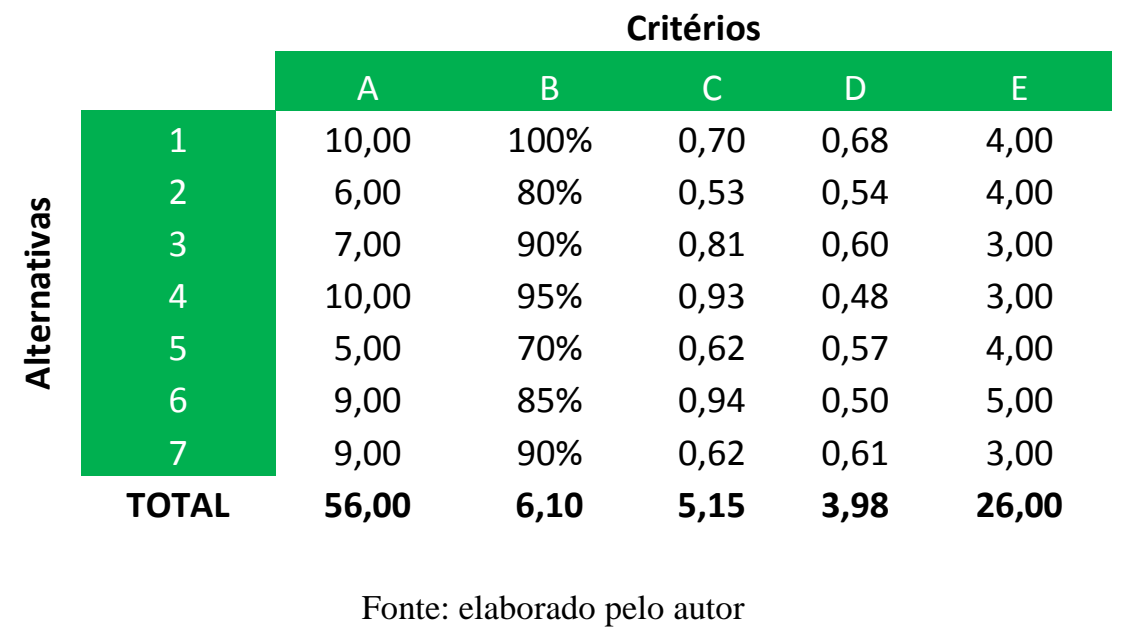

A figura 7 apresenta os valores observados para cada um dos critérios que estudamos anteriormente. Observem que dada um desses critérios se encontra em um escala diferente. Digamos que o critério A seja custo unitário de frete, ou seja, este critério é do tipo quanto menor melhor. Por outro lado, digamos que o critério B seja percentual de utilização dos veículos, ou seja, quanto maior melhor.

Para seguir em frente, vamos precisar normalizar os valores encontrados, colocando todos em uma mesma base (de zero a 1) para que possamos calcular o score final de cada alternativa. Com esse intuito, vamos dividir o valor observado de cada alternativa pelo valor total de todas as alternativas, quando o indicador for do tipo quanto maior melhor. Entretanto, quando o indicador for do tipo quanto menor melhor, teremos que fazer a normalização em duas fases:

1. Dividir a soma dos valores de todas as alternativas para aquele critério pelo valor observado de cada alternativa;

2. Com os novos valores calculados no passo anterior, dividir o valor de cada alternativa pelo valor total de todas as alternativas para aquele critério.

Efetuando essas operações, chegamos à figura 8: 
Figura 8: Valores normalizados

\begin{tabular}{|c|c|c|c|c|c|}
\hline & \multicolumn{5}{|c|}{ Critérios } \\
\hline & A & B & C & D & $\mathrm{E}$ \\
\hline 1 & 0,11 & 0,16 & 0,14 & 0,12 & 0,15 \\
\hline 2 & 0,18 & 0,13 & 0,19 & 0,15 & 0,15 \\
\hline 3 & 0,15 & 0,15 & 0,12 & 0,13 & 0,12 \\
\hline 4 & 0,11 & 0,16 & 0,11 & 0,17 & 0,12 \\
\hline 5 & 0,21 & 0,11 & 0,16 & 0,14 & 0,15 \\
\hline 6 & 0,12 & 0,14 & 0,11 & 0,16 & 0,19 \\
\hline 7 & 0,12 & 0,15 & 0,16 & 0,13 & 0,12 \\
\hline TOTAL & 1,00 & 1,00 & 1,00 & 1,00 & 1,00 \\
\hline
\end{tabular}

Fonte: elaborado pelo autor

Após a realização da normalização dos dados, o valor total da soma dos valores das alternativas para cada critério deverá ser igual a um. Neste ponto, é possível calcular o score de cada alternativa utilizando os vetores de prioridade encontrados nos passos anteriores e apresentados na figura $\mathrm{Y}$, bastando multiplicar os valores normalizados pelo vetor encontrado para cada critério. Deste modo, chegamos à figura 9 com o ranking do exemplo em questão:

Figura 9: Ranking das alternativas

$\begin{array}{|cc|}\text { Alternativa } & \text { Pontuação } \\ \mathbf{2} & 0,17 \\ \mathbf{5} & 0,16 \\ \mathbf{7} & 0,15 \\ \mathbf{1} & 0,13 \\ \mathbf{3} & 0,13 \\ \mathbf{6} & 0,13 \\ \mathbf{4} & 0,12\end{array}$

Fonte: elaborado pelo autor

No exemplo utilizado para ilustrar o funcionamento do AHP, a melhor alternativa apresentada é a alternativa de número dois, com o score total de 0,17. Deste modo, podemos concluir que, com base nos critérios e pesos atribuídos pelos tomadores de decisões, a melhor alternativa encontrada é a alternativa de número dois. 


\section{Estudo de Caso}

Nesta seção apresenta-se o desenvolvimento de um modelo de avaliação comparativa de desempenho para uma indústria de gases industriais e medicinais presente em todo o território nacional. Serão detalhadas todas as etapas para a implantação do sistema de avaliação comparativa de desempenho com base no modelo definido no item 4.4 deste estudo.

\subsection{Escolha de critérios e indicadores e construção da hierarquia do modelo}

Através da pesquisa bibliográfica realizada e detalhada na seção 4.2.1 deste trabalho, foram identificados os principais indicadores de desempenho logístico utilizados e descritos na literatura. Com base nesse trabalho, foi realizada uma reunião junto aos executivos da empresa para identificar quais indicadores a empresa estudada já realiza a medição e quais seriam interessantes iniciar a medição.

Por fim, foram selecionados e classificados 11 indicadores de desempenho em três diferentes critérios. Segundo os tomadores de decisão, esses indicadores são suficientes para medir o desempenho dos PSLs. Eles foram selecionados de maneira a reduzir a complexidade para a obtenção de dados sem prejudicar a avaliação dos PSLs.

O grupo frisou que a facilidade de obtenção dos dados é um dos pontos cruciais para o sucesso da implantação em larga escala do método de avaliação comparativa de desempenho dos prestadores de serviços. Para eles, como a empresa trabalha em uma área geográfica muito extensa e com diversas filiais espalhadas pelo Brasil, quanto menor a dependência de informações manuais fornecidas pelas filiais, maior a garantia de sucesso na implantação do método.

O grupo buscou, com a menor quantidade de indicadores possíveis, atingir todos os aspectos relevantes para a operação da empresa. Foram selecionados indicadores que buscam medir o desempenho dos PSLs sem que haja 
redundância, ou seja, cada indicador deve representar um aspecto da operação. $\mathrm{Na}$ figura 10 é apresentado um diagrama com a hierarquia aplicada no modelo. 


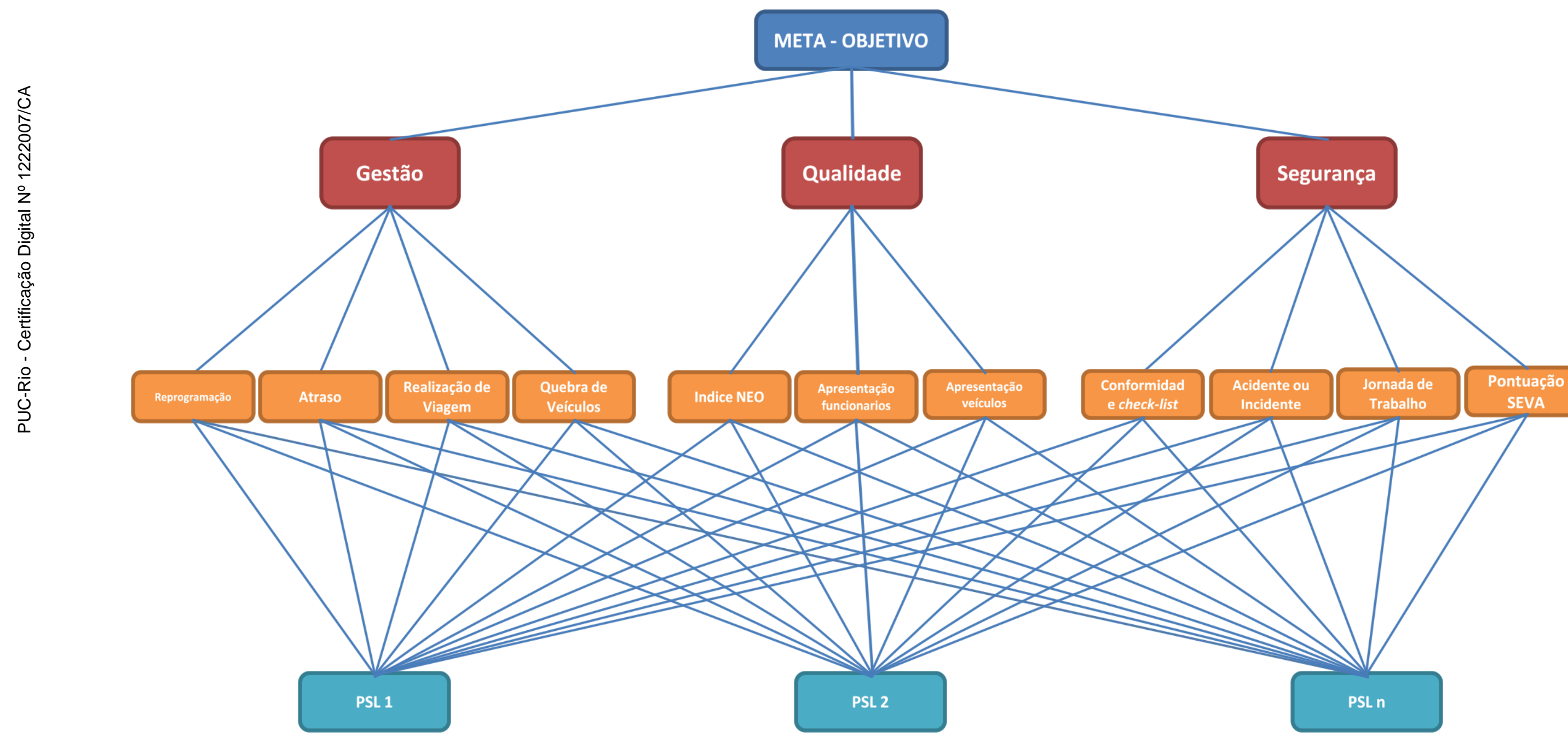

Figura 10: Hierarquia modelo proposto

Fonte: elaborado pelo autor 
Dos critérios existentes na literatura, o grupo selecionou os seguintes:

A. Gestão: considera indicadores que estão relacionados com a gestão da frota e dos funcionários do PSL, ou seja, onde é avaliado o desempenho pré/pós rotas;

B. Qualidade no atendimento: são avaliados os indicadores relacionados ao desempenho do PSL na execução do planejamento das viagens;

C. Segurança: é avaliado os indicadores que traduzem a o desempenho e a gestão dos PSLs no que tange a prevenção e desempenho em segurança.

A empresa estudada possui diversos indicadores de desempenho para controlar sua operação. Para fim deste projeto, o grupo buscou a quantidade mínima de indicadores que seja representativa para atingir os três critérios selecionados de maneira a medir o desempenho operação do PSL de maneira completa. $\mathrm{O}$ grupo selecionou os seguintes indicadores que traduzem o desempenho dos PSLs:

Critério Gestão: Dentro deste critério analisam-se os principais indicadores que o grupo entendeu que sofrem influência direta através de uma boa ou má gestão do PSLs. Foram escolhidos cinco indicadores que serão descrito abaixo:

A. Índice de reprogramação: É expressa a quantidade de entregas/visitas que foram programas para atendimento e que, por culpa do transportador, as mesmas não foram realizadas. $\mathrm{O}$ indicador é calculado dividindo a soma das entregas não realizadas pelo total das entregas programadas para o período.

B. Atraso na saída de veículo: É calculada a quantidade de atrasos nas saídas dos veículos provocados por problemas dos prestadores de serviço dividindo essa quantidade pelo total de viagens programadas no período analisado.

C. Não realização de viagem: Mede o desempenho do PSL no que diz respeito ao cumprimento das viagens programadas. É calculada a quantidade de viagens que não foram realizadas por culpa do transportador e dividido pela quantidade de viagens que foram programadas para aquele transportador no período analisado. 
D. Quebra de veículos: Embora o principal impacto da quebra dos veículos seja a necessidade de reprogramação de entrega junto aos clientes, o grupo entendeu que é importante inserir um indicador específico para quebra de veículos, pois ela também impacta o nível de satisfação dos clientes, mesmo quando não há uma necessidade de reprogramação para outro dia, muitas vezes é necessário negociar junto ao cliente um atendimento em horário diferenciado ou fora do horário comercial. Este indicador é calculado através da divisão do total de quebras de veículos pelo total de viagens programadas no período de análise.

Critério Qualidade no Atendimento: Neste grupo foram selecionados três indicadores que influenciam diretamente a qualidade do serviço prestado, são eles:

E. Índice NEO: Pesquisa realizada através dos comutadores de bordo dos veículos (on board computer - OBC), após o final do atendimento o cliente é questionado para atribuir notas para aqueles atendimentos. São realizadas $\mathrm{X}$ perguntas e os clientes devem atribuir uma nota de zero a cinco para aquele atendimento.

F. Apresentação dos funcionários: O gerente ou supervisor da unidade onde aquele transportador efetua a prestação de serviço deve atribuir uma nota de zero a cinco para a apresentação dos funcionários. São considerados fatores como: estado dos uniformes, estado dos equipamentos de proteção individual (EPI), tratamento com funcionários e clientes, etc.

G. Aspecto visual do veículo: Como no indicador F, este também é atribuído pelo gerente ou supervisor da unidade onde o transportador presta serviço. São considerados fatores como: limpeza dos veículos, estado da identificação visual, etc.

Critério Segurança: Para este grupo foram selecionados indicadores que auxiliem a traduzir o desempenho do PSL no quesito segurança. Na empresa analisada este quesito é de extrema importância, o que poderá ser verificado nos 
pesos atribuídos pelo tomador de decisão que será apresentado na próxima seção. Para este tema foram selecionados mais quatro indicadores.

H. Pontuação SEVA: A empresa analisada utiliza um sistema chamado SEVA que faz o monitoramento do veículo e da condução do motorista. São gerados eventos como:

I. Aceleração lateral: Através de um equipamento chamado acelerômetro, é verificado a força $\mathrm{G}$ emitida pelo veículo ao entrar em uma curva. Em estudo realizado pela empresa analisada, identificou-se que esse é um dos principais motivos de tombamento de veículos e foi configurado para que acima de $0.28 \mathrm{~g}$ seja atribuída uma infração ao motorista condutor.

II. Aceleração e freada brusca: utilizando o mesmo equipamento descrito acima, são computadas infrações caso o motorista acelere ou freie bruscamente, para isso é considerado movimentos com força superior a $8 \mathrm{KM} / \mathrm{h}$ por segundo.

III. Excesso de velocidade: o sistema é composto de um tacógrafo digital que é capaz de medir a velocidade exata do veículo. Além disto, o equipamento possui a informação de acionamento do limpador do para-brisa. Com isso, são gerados eventos de excesso de velocidade para veículos acima de $75 \mathrm{~km} / \mathrm{h}$ em pista seca e $65 \mathrm{~km} / \mathrm{h}$ em pista molhada.

Com base nos infrações detalhadas acima, é criado um score card onde todo motorista inicia o mês com 100 pontos. A pontuação de cada motorista é reduzida em função das infrações cometidas, os pesos atribuídos para cada infração e a distancia percorrida. Neste indicador iremos fazer uma média da pontuação no SEVA de todos os motoristas daquele prestador de serviço.

I. Jornada de trabalho: $\mathrm{O}$ sistema de monitoramento detalhado acima é capaz, também, de controlar as jornadas de trabalho e descanso semanal dos motoristas. Com isso, é calculado o indicador de jornada de trabalho, obtido através da divisão do total de não 
conformidades apresentadas dividido pelo total de viagens programadas para aquele prestador de serviço.

J. Índice não conformidade no checklist mensal: Mensalmente, por normas da empresa analisada, todos os veículos dos transportadores passam por um checklist onde é verificado o estado de itens dos veículos (ex: estados dos pneus, kit de emergência, cones de sinalização, etc.). Desta forma, o índice de não conformidade é calculado através do somatório de todos os checklist onde foram encontradas não conformidades divido pelo total de checklist realizados.

K. Acidente / Incidente: Calculado através da divisão do número total de acidentes e incidentes com os veículos do transportador pelo total de viagens realizadas pelo mesmo no período analisado.

Após a seleção dos indicadores e critérios que serão avaliados para todos os PSL, o grupo desenvolveu a tabela 7 , que apresenta a forma de obtenção dos dados:

1. Bases históricas dos sistemas existentes;

2. Bases históricas geradas manualmente;

3. Avaliação dos gestores.

Além disto, a tabela 7 classifica o indicador conforme seu tipo, ou seja, se ele é do tipo quanto maior melhor é o resultado ou se é do tipo quanto menor melhor o resultado. 
Tabela 7: Características dos indicadores

$\begin{array}{llll}\text { Critério } & \text { Indicador } & \text { Forma de Obtenção } & \begin{array}{l}\text { Tipo de } \\ \text { Indicador }\end{array} \\ \text { Gestão } & \text { Índice de reprogramação } & \text { Dados históricos - Sistema } & \text { Menor melhor } \\ \text { Gestão } & \text { Atraso na saída de veículos } & \text { Dados históricos - Sistema } & \text { Menor melhor } \\ \text { Gestão } & \text { Não realização de viagem } & \text { Dados históricos - Sistema } & \text { Menor melhor } \\ \text { Gestão } & \text { Quebra de veículo } & \text { Dados históricos - Manuais } & \text { Menor melhor } \\ \text { Qualidade } & \text { Índice NEO } & \text { Dados históricos - Sistema } & \text { Maior melhor } \\ \text { Qualidade } & \text { Apresentação dos funcionários } & \text { Avaliação dos gestores } & \text { Maior melhor } \\ \text { Qualidade } & \text { Aspecto visual do veículo } & \text { Avaliação dos gestores } & \text { Maior melhor } \\ \text { Segurança } & \text { Pontuação seva } & \text { Dados históricos - Sistema } & \text { Maior melhor } \\ \text { Segurança } & \text { Jornada de Trabalho } & \text { Dados históricos - Sistema } & \text { Menor melhor } \\ \text { Segurança } & \text { Não conformidade checklist } & \text { Dados históricos - Manuais } & \text { Menor melhor } \\ \text { Segurança } & \text { Acidente / Incidente } & \text { Dados históricos - Sistema } & \text { Menor melhor }\end{array}$

Fonte: elaborado pelo autor

Após a definição do método de análise multicritério e da definição dos critérios e indicadores, foi iniciado o trabalho de estruturação da hierarquia e definição dos pesos de cada critério e indicador conforme modelo proposto por Saaty (1990).

\subsection{Comparações pares a pares}

Feita a definição dos critérios que deverão ser avaliados e dos indicadores que traduzem o desempenho do PSL nestes critérios e após construção da hierarquia do modelo, se faz necessário seguir a estrutura do modelo proposto por Saaty (1990) onde são realizadas as comparações entre os pares para que seja possível a definição dos vetores de prioridade para cada indicador/critérios. Neste passo foi decisiva a participação do diretor de operações, que foi selecionado como tomador de decisão para o problema de avaliação de prestadores de serviços logísticos. Embora o modelo de Saaty (1990) proponha a criação de um grupo de especialistas para as avaliações pareadas, entende-se que o objetivo final da ferramenta é a identificação de PSLs com melhor desempenho que precisam ser 
reconhecidos e os com pior desempenho onde é necessário direcionar esforços para substituição ou melhoria do serviço prestado. Tendo em vista que o responsável por esse direcionamento é o diretor de operações, definiu-se que seria importante que apenas ele fosse o responsável pelas comparações, garantindo que o resultado estaria alinhado com suas expectativas.

Visto que a aplicação da comparação de todos os pares é muito trabalhosa, tende a criar inconsistências e ainda pouca disponibilidade deste funcionário, foi comparado apenas o triângulo superior das matrizes de comparação para cada critério, fazendo a matriz simétrica no triângulo inferior e supondo a consistência. Este método de avaliação é bastante aplicado no meio acadêmico e foi descrito por Wolff (2008).

Para facilitar as comparações pareadas, ao invés de enviar uma planilha com a matriz de comparações, foi criado um formulário de pesquisa utilizando a ferramenta de formulários do Google. Com isso, o tomador de decisão pode responder às comparações sem a necessidade de acessar computador ou planilha Excel.

Foram realizadas as avaliações pelo tomador de decisão e foram calculados os vetores de prioridade para cada um dos critérios e indicadores. Os resultados estão representados nas tabelas 8, 9, 10 e 11 .

Tabela 8: Comparações entre critérios

\begin{tabular}{lccccc} 
& Gestão & Qualidade & Segurança & $\begin{array}{c}\text { Vetor } \\
\text { Prioridade }\end{array}$ \\
\hline Gestão & 1 & 3 & $1 / 2$ & 0,32 \\
Qualidade & $1 / 3$ & 1 & $1 / 4$ & 0,12 \\
Segurança & 2 & 4 & 1 & 0,56
\end{tabular}

Fonte: elaborado pelo autor

Tabela 9: Comparações indicadores para o critério Gestão

\begin{tabular}{lcccc|c}
\multicolumn{1}{c}{ GESTÃo } & Reprogramação & Atraso & $\begin{array}{c}\text { Realização } \\
\text { de Viagem }\end{array}$ & $\begin{array}{c}\text { Quebra de } \\
\text { Veículo }\end{array}$ & $\begin{array}{c}\text { Vetor } \\
\text { Prioridade }\end{array}$ \\
\hline Reprogramação & 1 & 4 & $1 / 3$ & 3 & 0,30 \\
Atraso & $1 / 4$ & 1 & $1 / 4$ & $1 / 2$ & 0,09 \\
Realização de Viagem & 3 & 4 & 1 & 2 & 0,45 \\
Quebra de Veículo & $1 / 3$ & 2 & $1 / 2$ & 1 & 0,16
\end{tabular}


Fonte: elaborado pelo autor

Tabela 10: Comparações indicadores para o critério Qualidade

\begin{tabular}{lccccc}
\multicolumn{1}{c}{ QUALIDADE } & $\begin{array}{c}\text { Índice } \\
\text { NEO }\end{array}$ & $\begin{array}{c}\text { Apresentação de } \\
\text { Funcionários }\end{array}$ & $\begin{array}{c}\text { Apresentação } \\
\text { de Veículos }\end{array}$ & $\begin{array}{c}\text { Vetor } \\
\text { Prioridade }\end{array}$ \\
\hline Índice NEO & 1 & 6 & 7 & 0,75 \\
Apresentação de Funcionários & $1 / 6$ & 1 & 2 & 0,15 \\
Apresentação de Veículos & $1 / 7$ & $1 / 2$ & 1 & 0,09
\end{tabular}

Fonte: elaborado pelo autor

Tabela 11: Comparações indicadores para o critério Segurança

\begin{tabular}{l|ccccc}
\multicolumn{1}{c}{ SEGURANÇA } & $\begin{array}{c}\text { Conformidade } \\
\text { chek-list }\end{array}$ & Acidente/Incidente & $\begin{array}{c}\text { Jornada } \\
\text { de } \\
\text { Trabalho }\end{array}$ & $\begin{array}{c}\text { Pontuação } \\
\text { Seva }\end{array}$ & $\begin{array}{c}\text { Vetor } \\
\text { Prioridade }\end{array}$ \\
Conformidade chek-list & 1 & $1 / 8$ & $1 / 5$ & $1 / 4$ & 0,05 \\
Acidente/Incidente & 8 & 1 & 6 & 7 & 0,65 \\
Jornada de Trabalho & 5 & $1 / 6$ & 1 & 2 & 0,18 \\
Pontuação Seva & 4 & $1 / 7$ & $1 / 2$ & 1 & 0,12 \\
& Fonte: elaborado pelo autor & & &
\end{tabular}

Feitas as comparações pareadas e calculados os vetores de prioridade, $o$ resultado foi apresentado ao tomador de decisão para verificar se estava de acordo com o esperado. Verificou-se que os resultados dos pesos ficaram dentro do esperado, traduzindo o sentimento do tomador de decisão em relação à importância de cada um na avaliação dos prestadores de serviços logísticos.

Após a validação dos pesos obtidos com a aplicação do método, se fez necessário o cálculo da razão de consistência, para verificar a consistência das respostas atribuídas pelo tomador de decisão. Para isso, foi realizado o procedimento descrito na seção 4.4 deste trabalho. As razões de consistências encontradas para as respostas dadas pelo tomador de decisão foram:

- Critérios: A consistência das respostas foi confirmada, pois foi apresentada uma razão de consistência igual a 0,016 , ou seja, inferior ao limite de 0,10 . 
- Gestão: A consistência das respostas foi confirmada, pois foi apresentada uma razão de consistência igual a 0,087 , ou seja, inferior ao limite de 0,10 .

- Qualidade: A consistência das respostas foi confirmada, pois foi apresentada uma razão de consistência igual a 0,028, ou seja, inferior ao limite de 0,10 .

- Segurança: A consistência das respostas foi confirmada, pois foi apresentada uma razão de consistência igual a 0,093, ou seja, inferior ao limite de 0,10 .

As avaliações realizadas pelo tomador de decisão foram acompanhadas pelo pesquisador, desta forma, o tomador foi orientado a cada comparação para observar as resposta dadas anteriormente e atribuir os pesos. $\mathrm{O}$ pesquisador acredita que este foi um fator de importância que garantiu uma boa razão de consistência nas respostas em apenas uma rodada de avaliação.

Calculados todos os vetores de prioridade e tendo a consistência das respostas do tomador de decisão verificada, o grupo partiu para a implantação do método utilizando dados reais obtidos da operação da empresa analisada.

\subsection{Avaliações dos PSLs}

Com a finalidade de testar o modelo criado nos passos anteriores, a equipe de trabalho selecionou uma unidade de grande porte com quatro prestadores de serviço logísticos para avaliar o desempenho destes PSLs utilizando o novo modelo. A escolha dessa filial foi considerada fundamental para garantir a qualidade das análises dos resultados obtidos na implantação do piloto. Fatores como proximidade, facilidade de acesso à informação, proximidade ao grupo de trabalho e número de veículos/prestadores de serviço foram avaliados para a escolha da filial da cidade do Rio de Janeiro como piloto.

A seleção desta filial pelo grupo foi baseada no fato que é uma das maiores filiais de empresa estudada, os tomadores de decisão trabalham dentro do prédio administrativo (o que auxilia na obtenção de dados) e o diretor de operações no passado foi o gerente responsável por essa unidade. Deste modo, o grupo possui bastante conhecimento sobre o desempenho dos PSLs que atuam na 
filial piloto, possui facilidade de acesso à informação e trata-se de uma unidade representativa em relação ao tamanho de sua operação.

Uma vez definidos os indicadores a serem medidos, seus pesos e o escopo para o projeto piloto, foi iniciado o processo de levantamento de dados para cálculo dos onze indicadores selecionados nas etapas anteriores. Como existem quatro indicadores que são obtidos de forma manual ou através de avaliação dos gestores das unidades de negócios, foi criada uma planilha padrão para que a filial piloto pudesse preencher durantes os trinta dias definidos para o teste.

Após o levantamento dos dados necessários para cálculo dos indicadores, os resultados foram inseridos dentro do modelo desenvolvido com a finalidade de confecção do "ranking dos prestadores de serviço logístico" e buscando selecionar o melhor PSLs dentre os avaliados no piloto.

A tabela 12 apresenta as avaliações realizadas para os prestadores de serviços considerando o critério Segurança:

Tabela 12: Resultado avaliação PSLs piloto - Segurança

\begin{tabular}{lcccc} 
PSL & $\begin{array}{c}\text { Conformidade } \\
\text { chek-list }\end{array}$ & Acidente/Incidente & $\begin{array}{c}\text { Jornada } \\
\text { de } \\
\text { Trabalho }\end{array}$ & $\begin{array}{c}\text { Pontuação } \\
\text { Seva }\end{array}$ \\
\hline PSL1 & $24,0 \%$ & $0,7 \%$ & $12,0 \%$ & 95,99 \\
PSL2 & $12,5 \%$ & $0,4 \%$ & $12,5 \%$ & 96,85 \\
PSL3 & $0,6 \%$ & $0,2 \%$ & $25,0 \%$ & 96,46 \\
PSL4 & $25,0 \%$ & $1,1 \%$ & $6,7 \%$ & 97,24 \\
& \multicolumn{4}{c}{ Fonte: elaborado pelo autor } \\
\end{tabular}

A tabela 13 apresenta as avaliações realizadas para os prestadores de serviços considerando o critério Qualidade no Atendimento:

Tabela 13: Resultado avaliação PSLs piloto - Qualidade

\begin{tabular}{|cccc} 
PSL & $\begin{array}{c}\text { Índice } \\
\text { NEO }\end{array}$ & $\begin{array}{c}\text { Qualidade } \\
\text { de Funciontação }\end{array}$ & $\begin{array}{c}\text { Apresentação } \\
\text { de Veículos }\end{array}$ \\
\hline PSL1 & 5,00 & 4,00 & 3,00 \\
PSL2 & 4,89 & 5,00 & 5,00 \\
PSL3 & 4,75 & 5,00 & 4,00 \\
PSL4 & 4,98 & 4,00 & 5,00
\end{tabular}

Fonte: elaborado pelo autor 
A tabela 14 apresenta as avaliações realizadas para os prestadores de serviços considerando o critério "Gestão":

Tabela 14: Resultado avaliação PSLs piloto - Gestão

Gestão

\begin{tabular}{c|cccc} 
PSL & Reprogramação & Atraso & $\begin{array}{c}\text { Realização } \\
\text { de Viagem }\end{array}$ & $\begin{array}{c}\text { Quebra } \\
\text { de } \\
\text { Veículo }\end{array}$ \\
\hline PSL1 & $0,33 \%$ & $13,33 \%$ & $0,48 \%$ & $0,95 \%$ \\
PSL2 & $0,17 \%$ & $3,33 \%$ & $0,22 \%$ & $0,48 \%$ \\
PSL3 & $0,48 \%$ & $5,00 \%$ & $0,67 \%$ & $1,43 \%$ \\
PSL4 & $0,17 \%$ & $16,67 \%$ & $0,37 \%$ & $0,71 \%$
\end{tabular}

Fonte: elaborado pelo autor

Depois de levantados todos os indicadores que precisam ser medidos para cálculo da pontuação dos PSLs e criação do ranking, foram iniciados os processos de cálculo explicados na seção 4.4 desta dissertação. Para isso, foram utilizados os pesos calculados através das comparações pareadas realizadas na seção 5.2.

Conforme descrito na tabela 7 na seção 5.1, observem que do total de onze indicadores, temos quatro que são do tipo quanto maior melhor. O cálculo deste tipo de indicador é diferente do cálculo de indicadores do tipo quanto menor melhor e foi descrito na seção 4.4 deste trabalho. A tabela 15 apresenta o resultado da pontuação por critério de todos os PSL, o resultado foi multiplicado por cem para facilitar o entendimento:

Tabela 15: Resultado avaliação PSLs piloto - Todos Critérios

\begin{tabular}{cccc} 
PSL & Segurança & Qualidade & Gestão \\
\hline PSL1 & 16,72 & 24,26 & 14,45 \\
PSL2 & 17,79 & 25,77 & 44,78 \\
PSL3 & 40,76 & 24,70 & 25,20 \\
PSL4 & 24,73 & 25,27 & 15,57
\end{tabular}

Fonte: elaborado pelo autor 
Posteriormente à montagem da tabela 15, o grupo de especialistas parou para avaliar o resultado obtido. Observou-se que, de acordo com o modelo desenvolvido, o melhor PSL para o critério Segurança na filial estudada é o PSL3, este fato foi de encontro com a expectativa de todos do grupo, pois este PSL é reconhecido pela empresa como um dos melhores neste critério. No critério Qualidade, o resultado foi bastante parecido, o melhor PSL com pontuação de 25,7743 pontos em uma escala de zero a cem também foi de encontro com o sentimento do grupo. Por último, observou-se que no critério Gestão o melhor PSL pela avaliação dos tomadores de decisão recebeu a maior pontuação através dos cálculos do modelo.

O pesquisador entende que, o fato dos resultados de cada critério após a aplicação do modelo ir de encontro com o sentimento dos tomadores de decisão, se dá pelo fato de a cultura e os objetivos da empresa estarem bem definidos no que tange ao desempenho em segurança e operações. Este é um fato positivo para o projeto, pois auxilia o modelo a ser aplicado em todas as filiais sem que haja uma disparidade muito grande de julgamento, visto que os pesos foram definidos pelo diretor de operações, poderia surgir um desalinhamento do objetivo geral entre as unidades ou até mesmo os colaboradores.

Com base nos resultados apresentados na tabela 15, foram realizados novos cálculos para chegar à tabela 16 com o ranking dos prestadores de serviço da filial piloto. A tabela foi obtida através da multiplicação dos valores encontrados na tabela 15 e os pesos atribuídos para cada critério na seção 5.2, o resultado foi multiplicado por cem para facilitar o entendimento.

Tabela 16: Ranking dos PSLs - Piloto 30 dias

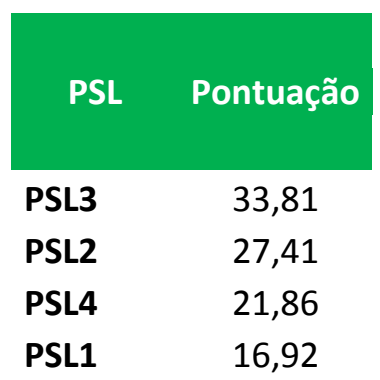

Fonte: elaborado pelo autor 
Conforme descrito na seção 5.1 deste trabalho, o critério Segurança foi o que obteve o maior peso no calculo do desempenho dos PSLs utilizando o AHP. Por consequência, observa-se que o prestador de serviço logístico que obteve a maior pontuação no ranking final do período de trinta dias de avaliação do piloto foi o PSL3, que também foi o melhor PSL no critério Segurança. Observa-se ainda que, embora o PSL2 tenha obtido a maior pontuação individual no critério Gestão (quarenta e quatro pontos), este não é o critério de maior impacto no ranking final.

\subsection{Análise de Robustez}

Posteriormente à geração da tabela 16, o grupo de trabalho se reuniu para avaliar os resultados obtidos e compará-los com o sentimento do grupo de trabalho formado na empresa estudada em função à avaliação pessoal de cada membro. Apesar de o grupo ter validado o ranking individual para cada critério, o resultado final gerou questionamentos por parte do gerente regional em função da nota do PSL2 finalizar 6,4 pontos abaixo do PSL3. Em sua opinião, o peso da segurança no resultado final foi muito grande.

Embora o tomador de decisão no que tange a troca de fornecedores de serviços logísticos e reconhecimento de bom desempenho seja o diretor de operações, o pesquisador optou por realizar uma nova comparação apenas entre os critérios com o gerente regional para verificar a disparidade exemplificada anteriormente e analisar a robustez do modelo proposto. Julgou-se que as comparações entre indicadores não se faz necessárias, pois, nas análises individuais de cada critério, os resultados obtidos foram aprovados em consenso por todos do grupo, não existindo nenhum questionamento quanto aos resultados obtidos.

Desta forma, foram realizadas as comparações apenas entre os critérios. A tabela 17 representa as respostas do gerente regional, o vetor de prioridade obtido e, na última coluna, o vetor de prioridade obtido com a resposta do tomador de decisão. 
Tabela 17: Comparações entre critérios Gerente Regional

$\begin{array}{lccccc} & \text { Gestão } & \text { Qualidade } & \text { Segurança } & \begin{array}{c}\text { Vetor } \\ \text { Prioridade }\end{array} & \begin{array}{c}\text { Tomador } \\ \text { de Decisão }\end{array} \\ \text { Gestão } & 1 & 4 & 1 / 2 & 0,36 & 0,32 \\ \text { Qualidade } & 1 / 4 & 1 & 1 / 3 & 0,13 & 0,12 \\ \text { Segurança } & 2 & 3 & 1 & 0,51 & 0,56\end{array}$

Fonte: elaborado pelo autor

Após os resultados obtidos das comparações pareadas realizadas pelo gerente regional observou-se que a ordem das prioridades não foi alterada em relação às comparações realizadas pelo tomador de decisão. Porém, observamos que o critério Segurança para o gerente regional possui um peso inferior se comparado ao tomador de decisão.

Após o cálculo dos pesos a partir das comparações pareadas realizadas pelo gerente regional, foi calculada a razão de consistência das respostas atribuídas pelo gestor. A razão encontrada foi de 0,034 que, embora maior que a obtida com a resposta do tomador de decisão $(0,016)$, é inferior ao limite estabelecido de 0,10 e, portanto, aceitável.

Tendo em vista a diferença de pesos obtida através da realização das comparações com outro colaborador, o pesquisador optou por realizar novamente os cálculos para obter o ranking com base nos pesos calculados através das respostas do gerente regional. A tabela 18 apresenta o resultado alcançado:

Tabela 18: Ranking dos PSLs para Ger. Regional - Piloto 30 dias

\begin{tabular}{|ccc} 
PSL & Pontuação & $\begin{array}{c}\text { Tomador } \\
\text { de } \\
\text { Decisão }\end{array}$ \\
\hline PSL3 & 33,10 & 33,81 \\
PSL2 & 28,53 & 27,41 \\
PSL4 & 21,50 & 21,86 \\
PSL1 & 16,87 & 16,92
\end{tabular}

Fonte: elaborado pelo autor 
Observou-se que houve uma pequena aproximação do segundo colocado no ranking em relação ao primeiro. Conclui-se que isso se deu, pois a cultura de segurança na empresa estudada é bastante difundida por todos os executivos, está bastante enraizada e, mesmo com a pequena diferença apresentada entre a avaliação dos colaboradores, este critério continua sendo de extrema importância para a organização e deve impactar diretamente na avaliação de desempenho dos prestadores de serviço.

Diante disto, o resultado foi apresentado para o grupo de trabalho. O gerente regional se mostrou impressionado e convencido que, embora na avaliação dele o critério Gestão possui um peso inferior, esse resultado não chega a impactar no resultado final do ranking. Desta forma, o grupo optou por validar o processo proposto utilizando as comparações realizadas pelo diretor de operações, pois este é, de fato, o tomador de decisão para o problema em questão.

Após analisar o resultado de cada indicador, critério e o ranking final, o grupo verificou que os valores encontrados estavam de encontro com as suas experiências e o conhecimento adquirido da operação de cada PSLs. Deste modo, o piloto foi considerado satisfatório pelo grupo e o modelo considerado pronto para implantação nas outras unidades da empresa.

Por fim, o resultado do piloto foi apresentado para o diretor de operações e o mesmo validou todo o processo e os resultados. Para ele, a ferramenta "chegou ao mesmo resultado que esperava através da minha experiência com a operação e foi capaz de classificar o desempenho dos prestadores de serviço de maneira adequada".

Foi definido pelo tomador de decisão que o modelo deverá ser aplicado em todas as unidades para os prestadores de serviço logísticos que possuam mais de dois veículos na operação e a ferramenta deverá ser utilizada para direcionar esforços para a troca de PSLs que obtiveram valores baixos de desempenho calculados através da ferramenta e para o reconhecimento dos PSLs que obtiverem os maiores valores na analise da ferramenta. 


\section{Conclusão}

Diante de um cenário em que a terceirização logística é cada vez mais difundida nas empresas, em função da sua importância estratégica para atingir os objetivos organizacionais e para que as organizações sejam capazes de focar em suas atividades fins, se faz necessária a avaliação não subjetiva do desempenho de seus PSLs.

Fernandez (2007) destaca que a tomada de decisão em logística possui uma série de variáveis, o que torna essa atividade extremamente complexa e trabalhosa. Portanto, se faz necessário o desenvolvimento de um modelo capaz de auxiliar o tomador de decisão a medir o desempenho dos PSL, tendo em vista que estes são responsáveis por executar uma atividade estratégica e importante para a organização.

Portanto, emerge a necessidade de se desenvolver um modelo estruturado de avaliação comparativa de desempenho dos PSLs que seja capaz de auxiliar as organizações na tomada de decisão no que tange a terceirização logística. O desenvolvimento do modelo, objeto deste estudo, foi obtido através de buscas no meio acadêmico de bases para o desenvolvimento de uma ferramenta que seja passível de ser utilizada no cotidiano de uma organização real, fazendo a integração de mundos que muitas vezes estão distantes.

Os resultados obtidos com o desenvolvimento do modelo e aplicação do projeto piloto mostraram que o objetivo geral do trabalho foi alcançado, uma vez considerando que o modelo possui uma estrutura simples, robusta e de fácil implantação na empresa. Além disto, o modelo se mostrou ser capaz de avaliar indicadores quantitativos e qualitativos, de maneira a traduzir a experiência do tomador de decisão e criar um ranking de todos os PSLs contratados pela empresa.

Os resultados também foram considerados satisfatórios para os objetivos específicos uma vez que foram realizadas pesquisas bibliográficas no meio acadêmico, selecionado o modelo mais adequado ao problema, desenvolvido o modelo e, por fim, aplicado em um piloto de trinta dias onde foi gerado o ranking final dos PSLs. 
A estrutura da metodologia AHP aplicada demonstrou ser bastante satisfatória para aplicação no estudo de caso devido à sua facilidade de aplicação, uma vez que:

- Estruturação do problema realizada de forma simples mesmo por pessoas que não tinham conhecimento da metodologia;

- Mostrou transparência no processamento e obtenção dos resultados;

- Proporcionou um ranking para as alternativas;

- Leva em consideração a importância de um critério em relação a outro.

A composição da equipe de trabalho é fundamental para atingir o resultado uma vez que todos os selecionados conhecem o tema e os PSLs avaliados. Os resultados atingidos refletem a percepção e os valores do tomador de decisão, desta forma entende-se que a escolha de apenas o diretor de operações para realizar as comparações pareadas entre critérios também se mostrou uma escolha acertada, embora seja uma adaptação do modelo proposto por Saaty (1990). Entretanto, foi possível comprovar a robustez das comparações realizadas pelo tomador de decisão ao se realizar as comparações com outro funcionário na análise de robustez do modelo, onde se apresentou resultado bastante semelhante.

Entende-se, ainda, que a seleção de somente um tomador de decisão para realizar as comparações pareadas foi correta, pois evitou excesso de comparações e uma possível dispersão dos resultados obtidos. Outro fator importante para a análise dos resultados foi a seleção da unidade piloto, pois os integrantes do grupo possuíam amplo conhecimento da operação dos PSLs naquela unidade.

O ranking final calculado com base nas avaliações realizadas pelo tomador de decisão e pelo resultado dos indicadores medidos durante o piloto foi questionado apenas por um integrante do grupo. Para verificar a robustez do modelo, esse integrante foi convidado a refazer as comparações pareadas. O resultado calculado com base nas respostas desse integrante foi de encontro com o resultado obtido através das respostas do tomador de decisão. Desta forma o grupo validou o resultado obtido.

Após a aplicação do método na unidade piloto, a empresa aprovou os resultados obtidos e optou por implantar o modelo em todas as suas unidades, 
distribuídas em todo o território brasileiro. Para a empresa, o modelo é de grande utilidade, visto que antes de sua criação não existia uma ferramenta para análise dos desempenhos dos PSLs. Sua avaliação era realizada de maneira não estruturada e subjetiva.

O modelo anterior se mostrava ineficiente para comparar PSLs de diferentes unidades e, com isso, não era possível direcionar esforços para aperfeiçoar o desempenho dos piores PSLs a nível Brasil, pois a avaliação era realizada localmente. Por outro lado, a empresa também não tinha capacidade de selecionar o melhor PSLs a nível Brasil, pois essa avaliação era feita de maneira subjetiva e localmente em cada unidade operacional.

É importante destacar que os executivos da empresa identificaram que a implantação do modelo é de extrema importância para empresa e para o processo de melhoria do serviço prestado e para tomada de decisões estratégicas no que tange à substituição de prestadores de serviços logísticos. A empresa julgou que o modelo é perfeitamente viável para implantação em todas as unidades do Brasil.

A utilização do método AHP se mostrou capaz de auxiliar o tomador de decisão a avaliar todos os PSLs de maneira única, sendo capaz de desenvolver um ranking de desempenho único para todo o Brasil. Assim, possibilitando o direcionamento de esforços para aperfeiçoar os PSLs com pior resultado no ranking e reconhecer o desempenho dos melhores PSLs identificados.

No que tange a pesquisas futuras, a própria empresa estudada irá avaliar a implantação do modelo em outras operações logísticas terceirizadas que não foram foco deste trabalho. Além disso, sugere-se que, a partir do modelo proposto, sejam elaborados modelos para medir o desempenho de PSLs de empresas em outras áreas, visto que cada negócio ou empresa apresenta características específicas e cultura diferenciada.

Acredita-se ainda que um trabalho semelhante para avaliação comparativa de desempenho dos motoristas e ajudantes dos PSLs seja interessante buscando reconhecer os que possuem melhor desempenho e identificar aqueles que estão com baixo desempenho.

Outra sugestão para trabalhos futuros é a realização de benchmarking entre as empresas de gases industriais e medicinais de forma que seja criado um modelo único de avaliação e, portanto, seja possível comparar o desempenho dos PSLs 
não apenas no ambiente organizacional, mas também em todo o setor em que atua. 


\section{Referências bibliográficas}

ANGELO, L. B. Indicadores de desempenho logístico. Grupo de estudos logísticos (GELOG) da Universidade Federal de Santa Catarina. 2005. Disponível em

<http://pessoal.utfpr.edu.br/anacristina/arquivos/A6\%20Textolndicadores. pdf>. Acesso em: 15 mar. 2014.

ARAUJO, M. Modelo Integrado para Seleção e Avaliação de Desempenho de Fornecedores. 2012. Dissertação (Mestrado em Engenharia de Produção) -

Programa de Pós-Graduação em Engenharia de Produção, Universidade Federal de Pernanbuco, Recife, 2012.

BALLOU, R. H. Gerenciamento da cadeia de suprimentos: planejamento, organização e logística empresarial. Porto Alegre: ed. Bookman, 2001.

BERNROIDER, E.; STIX, V. A method using weight restrictions in data envelopment analysis for ranking and validity issues in decision making. Computers \& Operations Research, v. 34, n. 9, p. 2637-2647, 2007.

BRANS, J. P.; MACHARIS, C.; MARESCHAL, B. The GDSS PROMETHEE procedure: a PROMETHEE-GAIA based procedure for group decision support, Journal of Decision Systems, v. 7, p. 283-307, 1998.

CARVALHO, R. A., COSTA, H. G. Classificação de Fornecedores por Fuzzy Logic. In: XVIII Encontro Nacional de Engenharia de Produção, 1998, Niterói. Anais...Niterói: Universidade Federal Fluminense, 1998.

CHARNES, A.; COOPER, W. W.; RHODES, E. Measuring the efficiency of decision

making units. European Journal of Operational Research, v. 2, n. 6, p. 429-444, 1978.

CHENG, Y. H.; LEE, F. Outsourcing reverse logistics of high-tech anufacturing firms by using a systematic decision-making approach: TFTLCD sector in Taiwan. Industrial Marketing Management, v. 39, p. 1111-1119, 2010.

CHOW, G.; HEAVER, T. D.; HENRIKSSON, L. E. Logistics performance: definition and measurement. International Journal of Physical Distribution \& Logistics Management, Bradford, v. 24, n. 1, p. 17-28, 1994. 
DEBREU, G. The Coefficient of Resource Utilization Econometrica, v. 19, n. 3, p. 273-292, 1951.

DECENZO, David; ROBBINS, Stephen. Administração de recursos humanos. 6 ed. Rio de Janeiro: LTC, 2001.

DORNIER, P. E. et al. Logística e operações globais: textos e casos. São Paulo: ed. Atlas, 2000.

DRUCKER, P. F. O melhor de Peter Drucker: a administração. São Paulo: Nobel, 2002.

ENTANI, T. Analytic hierarchy process based on interval analysis. IEEE, 2001.

Disponível em: $<$ http://ieeexplore.ieee.org/xpl/freeabs_all.jsp?arnumber=1009115>. Acesso em: 15 abr. 2014.

FAHEY, L. Gestão estratégica: o desafio empresarial mais importante da atualidade. In: FAHEY, L.; RANDALL, R. M. (Org.) MBA: curso prático de estratégia. 1. ed. Rio de Janeiro: Campus, 1999.

FARIA, A. Terceirização: um desafio para o movimento sindical. In: Terceirização: diversidade e negociação no mundo do trabalho. São Paulo: Hucitec, 1994.

FARREL, M. J. The Measurement of Productive Efficiency, Journal of the

Royal Statistical Society, Series A, v. 120, n. III, 253-281, 1957.

FERNANDEZ, A. M. P. Proposta de um modelo para medição do desempenho logístico apoiado pela lógica difusa: o caso de uma indústria de motores. 2007. 150 f. Dissertação (Mestrado em Administração) - Programa de Pós-Graduação em Administração, Universidade do Vale do Rio dos Sinos, São Leopoldo, 2007.

FLEURY, P. F.; LAVALLE, C. R. Logística Empresarial: A Perspectiva Brasileira. São Paulo, Atlas, 2000.

GIOSA, Livio A. Terceirização - Uma Abordagem Estratégica. 5쯔 Ed. São

Paulo Editora Pioneira,1997.

GIOSA, Lívio. IV Pesquisa Nacional sobre Terceirização nas Empresas - 2006. 2006. Disponível em: <http://www.sindeprestem.com.br/v2/cms/UserFiles/File/LivioGiosaResulta dolVPesqui saNacionalsobreTerceirizacao2006.doc $>$. Acesso em: 03. Mar. 2014. 
GOMES, L. F. A. M. Teoria da Decisão - Coleção Debates em

Administração. São Paulo: ed. Thomson Learning, 2007.

GUNASEKARAN, A.; PATEL; C.; TIRTIROGLU, E. Performance measures and metrics in a suply chain environment. International Journal of Operations \& Production Management, Bradford, v. 21, n.12, p. 71-87, 2001.

HANDFIELD, R. B.; NICHOLS, E. L. Introduction to Supply Chain Management. Saddle River: Prentice Hall, 1999.

HOLMBERG, S. A systems perspective on supply chain measurements.

International Journal of Physical Distribution \& Logistics

Management, Bradford, v. 30, n. 10, p. 847-868, 2000.

JOHNSTON, R.; CLARK, G. Administração de Operações de Serviço.

São Paulo: Atlas, 2002.

KAPLAN, R.S.; NORTON, D. P. A estratégia em ação: Balanced Scorecard. 17. ed. Rio de Janeiro: Campus, 1997.

KRAKOVICS, F. et al. Defining and calibrating performace indicators of a 4PL in the chemical industry in Brazil. International Journal of

Production Economics, v. 115, n. 2, p. 502-514, 2008.

LAUDON, K. C.; LAUDON, J. P. Management Information Systems: Organization and Technology in the Networked Enterprise. 6. ed. Prentice Hall, 2000.

LEDIOT, O.; WOLF, M. Robust performance hypothesis testing with the Sharpe ratio. Journal of Empirical Finance, v. 15(5):850-859, 2008.

LIEDTKA, S. L. Analytic Hierarchy process and multi-criteria performance management systems. Cost Management, v. 19, n. 6, p. 30-38, 2005.

LIMA JR., O. F. Análise e avaliação do desempenho dos serviços de transporte de carga. In: CAIXETA-FILHO, J. V.; MARTINS, R. S. (org.). Gestão logística do transporte de cargas. São Paulo: Atlas, 2001.

LIU, H. T.; WANG, W. K. An integrated Fuzzy approach for provider evaluation and

selection in third-party logistics. Expert Systems with applications, v. 38, p. 4387-4398, 2009.

MACEDO, M. A. S.; MANHÃES, J. V. P. Avaliação de Eficiência de Terminais de

Contêineres no Brasil através da Análise Envoltória de Dados (DEA).

Revista de

Negócios. v. 14, n. 3, art. 2, 2009. 
MEYER, M. W. Rethinking performance measurement: beyond the balanced scorecard. Cambridge, UK; New York: Cambridge University Press.

MEYER, M. W; EBRARY, INC. Rethinking performance measurement: beyond the balanced scorecard. Cambridge, UK; New York: Cambridge University Press, p.202, 2002.

NOVAES, A. G. Logística e gerenciamento da cadeia de distribuição. 3. ed. Rio de Janeiro: Elsevier, 2007.

PARMENTER, D. Winning KPIs revisited. New Zealand Management, v. 49 , p. 49- 51, 2002.

PEREIRA, M. T. Metodologia Multicritério para Avaliação e Selecção de Sistemas Informáticos ao Nível Industrial. Tese de Doutorado. Escola de Engenharia. Universidade do Minho. Portugal, 2003.

QUEIROZ, Evadio K. R. Qualidade segundo Garvin. São Paulo: Ed. Annablume, 1995

RAFAELI, L. A Análise Envoltória de Dados como ferramenta para avaliação do desempenho relativo. 2009. Dissertação (Mestrado em Engenharia de produção) - Programa de Pós-Graduação em Engenharia de Produção, Universidade Federal do Rio Grande do Sul, Porto Alegre, 2009.

ROBLES, L.; FISCHMANN, A. Características do Relacionamento entre Montadoras e Operadores Logísticos e a Prestação de Serviços de Logística Integrada na Indústria Automobilística no Brasil. In: Encontro Anual da ANPAD, 25., 2001, Campinas. Anais... Campinas: Associação Nacional dos Cursos de Pós-Graduação em Administração, 2001.

SAATY. T. L. Método de Análise Hierárquica. São Paulo: ed. McGrawHill, Makron, 1991. . How to make a decision: the Analythic Hierarquy Process. Interfaces, v. 24, n. 6, p. 19-43, 1994.

Decision Making - the Analytic Hierarchy and Network Processes (AHP/ANP). Journal of Systems Science and Systems Engineering, v. 13, n. 1, p.1-34, 2004.

of the $V$

Fundamentals of the Analytic Network Process, Proceedings

ISAHP, 48-63. 1999 
SALERNO, M. S. Organização do trabalho e da produção: flexibilidade e terceirização. In: ENCONTRO NACIONAL DE ESTUDOS DO TRABALHO, 3., 1994, Rio de Janeiro. Anais... Rio de Janeiro: ABET Associação Brasileira de Estudos do Trabalho, v. 1. p. 169-190, 1993.

SANTI, E. et al. Um Modelo Híbrido de Seleção de Fornecedores para Cadeias de Suprimentos. In: XLIII Simpósio Brasileiro de Pesquisa Operacional, 2011, Ubatuba. Anais... Ubatuba, 2011.

SANTOS, W. L. P.; MORTIMER, E. F. Tomada de Decisão para Ação Social Responsável no Ensino de Ciências. Ciência \& Educação, Bauru - SP, v. 7, n. 1, p. 95-111, 2001.

SANTOS, J.J. Análise de custos. São Paulo: ed. Atlas, 2000.

SÁ, M. P. et al. Terceirização no processamento final das indústrias farmacêutica e veterinária. In: ENCONTRO ANUAL DA ANPAD, XXI, 1997, Angra dos Reis. Anais... Angra dos Reis: ANPAD, 1997. produção industrial e de serviços. 1 CD-ROM.

SARKIS, J. e TALURRI, S. A model for strategic supplier selection, The Journal of Supply Chain Management: A Global Review of Purchasing and Supply, 38, 18-28, 2002.

SEYDEL, J. Data envelopment analysis for decision support. Industrial Management \& Data Systems, v.106(1), p. 81-95, 2006.

SILVA, L. S. Nível de serviço logístico: estudo de caso em uma empresa de bebidas da Paraíba. In: Encontro Nacional de Engenharia de Produção (ENEGEP), 28., 2008, Rio de Janeiro. Anais... Rio De Janeiro: Associação Brasileira de Engenharia de Produção, 2008.

SINUANY-STERN, Z.; MEHREZ, A.; HADAD, Y. An AHP/DEA methodology for ranking decision making units. International

Transactions in Operational Research. vol. 7, n. 2, p. 109-124, 2000.

SO, S. et al. Evaluating the service quality of third-party logistics service providers using the analytic hierarchy process. Journal of information systems and technology management, v. 3, n. 3, p. 261-270, 2006.

TRACEY, M. The role of logistics in strategic management. International Journal of Integrated Supply Management, v. 2, n. 4, p. 356382, 2006.

WEBER, C. A., CURRENT, J. R., DESSAI A. Non-cooperative negotiation strategies for vendor selection - European Journal of Operational Research, v. 108 p. 208-223, 1998. 
WOOD JR, T.; ZUFFO, P. K. Supply chain management. Revista de Administração de Empresas. São Paulo: FGV, vol. 38, 1998.

ZHANG, H.; ZHANG, G.; ZHOU, B. Research on selection of the third party logistic service providers. International Federation for Information Processing, v. 251, p. 211-221, 2007. 